\title{
5 Klaus Mann: Der Engel als Medium einer neuen Ordnung
}

Eine publizistische Verbindung zwischen den Exilanten Walter Benjamin und Klaus Mann ist nie zustande gekommen. „Der Autor als Produzent“ sollte 1934 in der von Klaus Mann herausgegebenen Zeitschrift Die Sammlung erscheinen, die Veröffentlichung scheiterte aber mutmaßlich an der Intervention von Heinrich Mann. Der Onkel lehnte die polemischen Spitzen und die in dem Text ausgemachte ausgeprägte Nähe zur kommunistischen Partei ab, ${ }^{1}$ auch mag ihm die abschätzige Erwähnung seiner Person aufgestoßen sein. ${ }^{2}$ In gewisser Weise steht diese nicht zustande gekommene Zusammenarbeit symptomatisch für die Unterschiede, die zwischen den Exilexistenzen von Benjamin und Mann bestehen. Denn obgleich Klaus Mann an einer Bündelung der antifaschistischen Kräfte über alle ideologischen Gräben hinweg gelegen war, so war seine Vorstellung, wie dieser Kampf geführt werden sollte, denkbar weit entfernt von der Benjamins. Damit ist wiederum auch eine grundsätzlich unterschiedliche Modellierung der Figur des Engels verbunden, auch wenn sie bei beiden als unmenschliches Gegengewicht zu der grassierenden Enthumanisierung auftritt.

In „Agesilaus Santander“ wie in den „Thesen“ wirkt der Engel als eine Figur der Verfremdung, der Zerstörung, des Unmenschlichen und, über diesen Umweg, als Medium der Erkenntnis, des Bewahrens, des von Benjamin proklamierten realen Humanismus. Seine Rolle als Bote kann der Engel dabei nur paradox ausüben, indem er nämlich mit der theologischen Tradition bricht, aus der die Zuschreibungen dieser Rolle erwachsen. Während Benjamins politisches Denken über Umwege verläuft und auch der Engel als Figur zwischen Apparatur und Apparition seine politische Bedeutung im Kontext des modernen Exils nur über Umwege erhält, führt der Engel in Klaus Manns Roman Der Vulkan. Roman unter Emigranten direkt ins politische Geschehen der 1930er Jahren. Ebenso schnörkellos wird auch der angelologische und vermeintlich anachronistische Kern der Engel reaktiviert: Angelehnt an das Buch Daniel erscheint ein Engel dem asketisch lebenden Kikjou und eröffnet ihm Einsichten in Gottes verborgenen Plan, in dem die Exilantinnen und Exilanten zu Trägerinnen und Trägern des göttlichen Willens erklärt werden.

1 Vgl. Chryssoula Kambas, Positionierung des Linksintellektuellen im Exil. In: BenjaminHandbuch. Leben - Werk - Wirkung, hg. von Burkhardt Lindner, Stuttgart 2011, S. 420-436, hier S. 431.

2 Vgl. Benjamin, Der Autor als Produzent, S. 689-690.

Ә Open Access. ( 2022 Lena Zschunke, publiziert von De Gruyter. (c) BY-SA Dieses Werk ist lizenziert unter einer Creative Commons Namensnennung - Weitergabe unter gleichen Bedingungen 4.0 International Lizenz. https://doi.org/10.1515/9783110552621-005 
Diese Reaktivierung von angelologischen Strukturen, die eine eschatologische Perspektive eröffnet, ist vor dem Hintergrund der Zeit zu verstehen. Mit den Verbrechen des Nationalsozialismus verlagert sich der Befund des Exils als prägendes Moment der Moderne mehr und mehr von geschichtsphilosophischen und metaphysischen Reflexionen in die Lebenswelt moderner Individuen, mit existentiellen Konsequenzen. Der souveräne Mensch, den kosmologische, evolutionsbiologische und psychoanalytische Erkenntnisse und dann die Erschütterungen des Ersten Weltkrieg bereits ins Wanken gebracht hatten, befindet sich nun, entwürdigt durch das Hitler-Regime und ohne das Auffangnetz der Staatsbürgerschaft, im freien Fall. Klaus Mann verstand seine Ausbürgerung durch das nationalsozialistische Deutschland 1934 zwar als „Ehre“, da sie „uns offiziell bestätigt, daß wir nichts zu tun haben mit seiner [Deutschlands, L.Z.] Schande“33. Allerdings bedeutete die Strafexpatriation eine „Vogelfreierklärung““4 die für die Betroffenen mit einschneidenden Folgen verbunden war. Zur Einschränkung der Freizügigkeit und der symbolischen, dabei nicht zu unterschätzenden Dimension der Ächtung traten in vielen Fällen bedrohliche Engpässe bei der Versorgung mit überlebenswichtigen Gütern. ${ }^{5}$

Die Praxis der Ausbürgerung stellt einen eminent modernen Vorgang dar. „Staatenlosigkeit ist das neueste Phänomen, die Staatenlosen sind die neueste

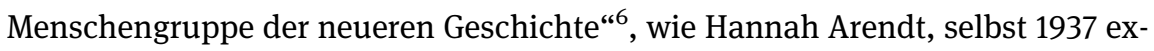
patriiert, in Elemente und Ursprünge totaler Herrschaft (1955) feststellt. Aus dem eigenen Land „als Auswurf der Menschheit“ vertrieben, wurden die Staatenlosen „überall auch als Auswurf der Menschheit empfangen“7. Mit der Vertreibung aus dem Staatsgebiet geht eine Vertreibung aus dem Bereich des Gesetzes einher. ${ }^{8}$ Im Zuge dieser Entwicklung erwies sich die völlige Unzulänglichkeit des Konzepts der Menschenrechte: „Das bloße Wort ,Menschenrechte“ wurde überall und für jedermann, in totalitären und demokratischen Ländern, für Opfer, Verfolger und Betrachter gleichermaßen, zum Inbegriff eines heuchleri-

3 Klaus Mann, Ich soll kein Deutscher mehr sein. In: Mann, Zahnärzte und Künstler. Aufsätze, Reden, Kritiken 1933-1936, hg. von Uwe Naumann u. Michael Töteberg, Reinbek 1993, S. 217218, hier S. 217.

4 Dieter Gosewinkel, Einbürgern und Ausschließen. Die Nationalisierung der Staatsangehörigkeit vom Deutschen Bund bis zur Bundesrepublik Deutschland, Göttingen 2001, S. 378. Zu den einzelnen Maßnahmen und ihren Auswirkungen vgl. Gosewinkel, Einbürgern und Ausschließen, S. 369-382.

5 Vgl. Gosewinkel, Einbürgern und Ausschließen, S. 379.

6 Hannah Arendt, Elemente und Ursprünge totaler Herrschaft, Frankfurt am Main 1958,

S. 416 .

7 Arendt, Elemente und Ursprünge totaler Herrschaft, S. 405.

8 Vgl. Arendt, Elemente und Ursprünge totaler Herrschaft, S. 402-405. 
schen oder schwachsinnigen Idealismus“" , wie Hannah Arendt bemerkt. Über das Bemühen, 1934 in Lausanne einen Staatenlosenpass zu schaffen, schreibt der passlose Klaus Mann in einem Brief an seine Mutter erbittert, es sei „natürlich genau so wenig geglückt, wie irgendetwas was der Völkerbund jemals in Angriff genommen hat" ${ }^{10}$. Das Warten auf überlebensnotwendige Papiere, die Flucht vor Verfolgung durch den immer länger werdenden Arm des NS-Regimes und der Kampf um die Bedürfnisse des täglichen Lebens erzwingen eine gesteigerte Aufmerksamkeit für die unmittelbare Umgebung.

Benjamins geschichtsphilosophische Reflexionen in „Über den Begriff der Geschichte“ werden dagegen, wie es explizit in der X. These heißt, aus einer weltabgewandten Haltung gewonnen. Trotz der Dringlichkeit der gegenwärtigen Situation bleiben sie dem Gedanken verpflichtet, dass revolutionäre Aktion nicht aus einer Vertiefung in die Gegenwart resultiert, sondern aus der Rückwendung zur Vergangenheit. Den weltabgewandten Klosterbrüdern, die Benjamin 1940 in seinen „Thesen“ bemüht, steht bei Klaus Mann 1939 der Appell an die Intellektuellen im nationalsozialistischen Deutschland gegenüber, sie mögen „unter die Leute“ gehen, „wie die Prediger des frühen Christentums es getan haben“11. Der Kunst als „höchste[m]“ Teil des Menschenlebens kommt für Klaus Mann eine Schlüsselrolle in den „Kämpfen seiner [des Menschenlebens, L.Z.] harten Gegenwart“"12 zu. Wenn sie nicht „absterben und ganz elend werden“ soll, muss sie „ins Getümmel springen“"13. Insbesondere die Literatur ist durch den Nationalsozialismus als eine genuin „antiliterarisch[e] Bewegung“14 in ihrer Existenz bedroht. Gleichzeitig stellt sie aber auch das Gegengift bereit, indem sie die Wahrheit verbreitet und tragfähige Utopien gegen den untergründigen Nihilismus des Nationalsozialismus setzt. Daher fordert Mann mehrfach Schriftstellerinnen und Schriftsteller im nationalsozialistischen Deutschland auf, die Waffe des

9 Arendt, Elemente und Ursprünge totaler Herrschaft, S. 406.

10 Klaus Mann, Brief an Katia Mann, 28. März 1934. In: K. Mann, Briefe und Antworten 1922 1949, hg. von Martin Gregor-Dellin, Reinbek 1991, S. 168-169, hier S. 168.

11 Klaus Mann, An die deutschen Intellektuellen. In: Mann: Zweimal Deutschland. Aufsätze, Reden, Kritiken 1938-1942, hg. von Uwe Naumann u. Michael Töteberg, Reinbek 1993, S. 161164, hier S. 164.

12 Klaus Mann, Situation der deutschen Literatur, drinnen und draußen. In: Mann, Zahnärzte und Künstler. Aufsätze, Reden, Kritiken 1933-1936, hg. von Uwe Naumann u. Michael Töteberg, Reinbek 1993, S. 87-107, hier S. 106.

13 Mann, Situation der deutschen Literatur, S. 106.

14 Klaus Mann, Die Aufgabe des Schriftstellers in der gegenwärtigen Krise. In: Mann, Zweimal Deutschland. Aufsätze, Reden, Kritiken 1938-1942, hg. von Uwe Naumann u. Michael Töteberg, Reinbek 1994, S. 263-271, hier S. 267. 
Wortes „für die gute Sache“15 einzusetzen, um „dem betrogenen deutschen Volk die Wahrheit zuzuflüstern“16.

Die unterschiedlichen Positionen Benjamins und Manns spiegeln sich auch in den Lebenswegen im Exil wider. Während Walter Benjamin in der Öffentlichkeit nach 1933 wenig präsent war, sind insbesondere Klaus Manns frühe Exiljahre von einer emsigen Geschäftigkeit geprägt. Allerdings bleibt auch seine publizistische Existenz prekär, bereits 1933 stellt er fest: „Wir sind arm. Unser Markt ist zerstreut über den Kontinent und über den ganzen Planeten. “17 Diese existenzbedrohende Entwicklung spitzt sich sukzessive zu, da der Markt für deutschsprachige Exilliteratur mit der deutschen Besetzung der Nachbarländer weiter schrumpft. Klaus Manns Zuversicht und sein Bemühen, zwischen den verschiedenen Exilgruppierungen zu vermitteln, erleiden außerdem durch die historischen Ereignisse einen empfindlichen Dämpfer. Insbesondere das Münchner Abkommen im September 1938 und der Hitler-Stalin-Pakt im August 1939, der auch Benjamin so tief erschütterte, sind für Mann einschneidende Zäsuren. Mit dem deutsch-sowjetischen Nichtangriffspakt wird zudem das Scheitern der Politik der antifaschistischen Einheitsfront evident, für die Klaus Mann sich bis dahin vehement eingesetzt hatte. ${ }^{18}$

In gewissem Sinne steht Klaus Manns Biographie exemplarisch für die intellektuelle Physiognomie der ersten Hälfte des 20. Jahrhunderts, mit dem Topos des modernen Exils in seinen zunächst vornehmlich innerlichen und dann immer mehr auch existentiellen Formen. Heute wird Klaus Mann vor allem als hellsichtiger Diagnostiker und leidenschaftlicher Gegner des Nationalsozialismus wahrgenommen, ,prescient in being always on the right side (against Hitler from the 1920s, critical of American anti-communism from the 1940s) and

15 Klaus Mann, An die Schriftsteller im Dritten Reich. In: Mann, Zweimal Deutschland. Aufsätze, Reden, Kritiken 1938-1942, hg. von Uwe Naumann u. Michael Töteberg, Reinbek 1994, S. 94-112, hier S. 112.

16 Mann, An die deutschen Intellektuellen, S. 163.

17 Klaus Mann, Drinnen und draußen. In: Mann, Zahnärzte und Künstler. Aufsätze, Reden, Kritiken 1933-1936, hg. von Uwe Naumann u. Michael Töteberg, Reinbek 1993, S. 69-73, hier S. 72.

18 Vgl. Uwe Naumann u. Michael Töteberg, Vorwort. In: Mann, Zweimal Deutschland. Aufsätze, Reden, Kritiken 1938-1942, hg. von Uwe Naumann u. Michael Töteberg, Reinbek 1994, S. 9-15, hier S. 10. So schrieb Klaus Mann etwa in einer Stellungnahme zu einer KPD-Broschüre im April 1939: „Die Einheitsfront aller antifaschistischen Kräfte ist, für mein Gefühl und für meine Erkenntnis, nicht nur eine Notwendigkeit, sondern eine Selbstverständlichkeit“ (Klaus Mann, Nach dem Sturze Hitlers. Ein Diskussionsbeitrag. In: Mann, Zweimal Deutschland. Aufsätze, Reden, Kritiken 1938-1942, hg. von Uwe Naumann u. Michael Töteberg, Reinbek 1994, S. 88-91, hier S. 88). 
courageous in fighting for his beliefs, as a writer and even as a soldier“19. Aber schon bevor er am 13. März 1933 Deutschland verließ und im November 1934 ausgebürgert wurde, thematisierte dieser „unruhig[e] Wanderer von Haus“ ${ }^{20}$ in seinen Schriften immer wieder den Zustand der Entortung. Neben Homosexualität und Künstlerbewusstsein ist sein Unverbundenheitsgefühl wie bei Rilke und Benjamin vor allem durch eine soziale und moralische Entwurzelung nach dem Ersten Weltkrieg bedingt. ${ }^{21}$ Auch die Kehrseite, die Sehnsucht nach Zugehörigkeit, ist Teil von Klaus Manns Werk, „innig - aber erfolglos - darum bemüht, den Anschluß an irgendeine Gemeinschaft $\mathrm{zu}$ finden, sich irgendeiner Ordnung einzufügen: immer schweifend, immer ruhelos, beunruhigt, umgetrieben, auf der Suche ...“22, wie er in seiner Autobiographie Der Wendepunkt (1949) schreibt. Gleichwohl griffe es zu kurz, in der Emigration Klaus Manns bloß den äußeren Vollzug eines innergesellschaftlichen Nomadentums zu erblicken. So engagiert sich Mann nach 1933 immer stärker politisch, ${ }^{23}$ wovon nicht nur die Briefe und Tagebuchaufzeichnungen Zeug-

19 Lara Feigel, Cursed Legacy: The Tragic Life of Klaus Mann - review. In: The Guardian, 2016 [https://www.theguardian.com/books/2016/mar/06/cursed-legacy-frederic-spotts-review-tra gic-life-of-klaus-mann-son-thomas-nazism-communism-suicide]. Selbst scharfe Kritiker seines Werks (und seiner Person), wie Marcel Reich-Ranicki, attestieren Klaus Mann überragenden politischen Weitblick (vgl. Marcel Reich-Ranicki, Schwermut und Schminke. In: Reich-Ranicki, Thomas Mann und die Seinen, München 2007, S. 323-348, hier S. 336-338).

20 Golo Mann, Erinnerungen an meinen Bruder Klaus. In: K. Mann, Briefe und Antworten 1922-1949, hg. von Martin Gregor-Dellin, Reinbek 1991, S. 629-661, hier S. 629.

21 Vgl. dazu insbesondere Der fromme Tanz (1925), Kind dieser Zeit (1932) oder Treffpunkt im Unendlichen (1932). Bereits 16-jährig (und nicht frei von Selbststilisierung) schreibt Klaus Mann an den Leiter der Odenwaldschule, Paul Geheeb: „Ich gebe ein nicht ganz kleines Stück von mir her, wenn ich Ihnen sage: Überall werde ich - Fremdling sein. Ein Mensch meiner Art ist stets und allüberall durchaus einsam - - - derlei führt zu weit“ (Klaus Mann, Brief an Paul Geheeb, 12. Juni 1923. In: Mann, Briefe und Antworten 1922-1949, hg. v. Martin Gregor-Dellin, Reinbek 1991, S. 14-15, hier S. 15).

22 Klaus Mann, Der Wendepunkt, Reinbek 2005, S. 591.

23 Zum Aspekt sozial-politischer Verantwortung in Klaus Manns Werk vgl. Mann, Der Wendepunkt, S. 291-293 sowie zu verschiedenen Beurteilungen von Kontinuität und Diskontinuität Birgit Fulton, Klaus Mann: Das Scheitern am „mißratenen Leben“. Untersuchungen zum Identitätskonstrukt Klaus Manns, Wien 2009, S. 297-304, S. 321-322 u. S. 357-359. Tobias Lachmann vertritt die These, dass sich „[e]rst im Entstehungsprozeß von Der Vulkan [...] ein Wandel in dieser Haltung zum Exil [vollzieht]: Die ursprüngliche, von der Verlusterfahrung gekennzeichnete Agitation gegen Hitler-Deutschland weicht der Profilierung einer kosmopolitischen Gegenposition, die den Verlust der einstigen Heimat in einen Gewinn umzumünzen vermag“ (Tobias Lachmann, Politische Schreib(-)Szene Exil. Zu Klaus Manns Emigrantenroman Der Vulkan. In: Die Schreibszene als politische Szene, hg. von Claas Morgenroth, Martin Stingelin u. Matthias Thiele, München 2012, S. 229-238, hier S. 234). 
nis ablegen; auch in einem gewandelten Verständnis des Exils in seinem Werk Der Vulkan von 1939 schlägt sich diese Entwicklung nieder.

Der Vulkan wurde immer wieder dezidiert als Exilroman rezipiert und gewürdigt, ${ }^{24}$ allerdings geht in dieser dokumentarischen Perspektive tendenziell die Spezifik seiner ästhetischen Eigenlogik verloren. So wurde in der Forschung vielfach festgestellt, dass der Roman auf ein breites, tendenziell unüberschaubares Figurenspektrum aufbaut und diverse Formen des Exils abbildet. ${ }^{25}$ Diese Ansicht deckt sich mit Klaus Manns Selbstauskunft, nach der der Vulkan den Versuch darstellt, „unsere soziologische und psychologische Lage in breiterem Rahmen episch zu analysieren“26. Die Besonderheit des Romans liegt jedoch darin, dass die analytisch-dokumentarische Ebene und ihr realhistorischer Bezug auf vielfältige Weise überschritten werden. Diese fundamentale Transzendierungsbewegung erstreckt sich auf nationalstaatliche Festlegungen, aber auch auf den entwürdigten Menschen selbst, der über ästhetische Angelisierungspraktiken aufgewertet wird. Insofern ist es nicht übertrieben zu sagen, dass es sich bei dem Vulkan um das „entscheidende Engelwerk Klaus Manns““27 handle.

Der Engel erscheint hier ganz klassisch als der „[V]on-oben-Gesandte“28, ausgestattet mit einer göttlichen Botschaft. Entsprechend ist im Vulkan auch das Ordnungssystem, dem der Engel entstammt, wieder eingesetzt: Es gibt einen Gott, der gegen Ende des Romans sogar selbst spricht. Da hier nicht bloß Formen und Figuren des Religiösen verwendet und einem modernen politischen Programm gemäß umbesetzt werden, sondern vielmehr auch explizit auf die Struktur eines göttlichen Heilsplans zurückgegriffen wird, ist der Vulkan in größerem Ausmaß von dem Verdikt des Anachronismus bedroht. So bedeutet die Reinstallierung des christlichen Heilsgedankens in Verbindung mit Manns realitätsverpflichtender Behauptung, eine analytische Durchdringung des Exils

24 So etwa von Andreas Grünes, der den Roman „zu den ehrgeizigsten Projekten der literarischen Verarbeitung des Exils“ zählt (Andreas Grünes, Klaus Mann: Der Vulkan. Roman unter Emigranten (1939). In: Handbuch der deutschsprachigen Exilliteratur. Von Heinrich Heine bis Herta Müller, hg. von Bettina Bannasch u. Gerhild Rochus, Berlin 2013, S. 435-441, hier S. 440).

25 Vgl. Christina Thurner, Der andere Ort des Erzählens. Exil und Utopie in der Literatur deutscher Emigrantinnen und Emigranten 1933-1945, Köln 2003, S. 180-182, S. 184-185 u. S. 191-192.

26 Klaus Mann, Brief an Hans Hamm, 18. April 1939. In: Mann, Briefe und Antworten 1922-1949, hg. von Martin Gregor-Dellin, Reinbek 1991, S. 375-377, hier S. 376.

27 Gunter Volz, Sehnsucht nach dem ganz anderen. Religion und Ich-Suche am Beispiel von Klaus Mann, Frankfurt am Main 1994, S. 180.

28 Klaus Mann, Der Vulkan. Roman unter Emigranten, Hamburg 2004, S. 518. Im Folgenden V. 
zu leisten, ein einigermaßen waghalsiges Unterfangen. Neben der Gefahr einer Diskreditierung des analytischen Anspruchs drohte mit der intellektuellen Irritation, die die Referenz auf eine christliche Ordnung hervorrufen musste, auch das fragile Gefüge des antifaschistischen Bündnisses in eine Schieflage zu geraten. Diese Gefahr sah auch Klaus Mann, der sich im April 1939 besorgt fragte: „Wird diese Freundschaft [mit den Kommunisten, L.Z.] halten? Wird man mir die Engel im ,Vulkan“ verzeihen?“29

Dass die Dimension des Religiösen auf den ersten Blick nicht in den politischen Exilkontext passt, zeigt Andreas Grünes Artikel im Handbuch der deutschsprachigen Exilliteratur (2013). Darin wird die Allgegenwärtigkeit religiöser Topoi, Strukturelemente und Redeweisen völlig ignoriert. In dieser Ausblendung des vermeintlich Anstößigen oder Bedeutungslosen tut man aber dem Roman keinen Gefallen. Denn auf diese Weise können seine rhetorisch-ästhetische Architektur, die Resemantisierung des Exils und das damit verbundene Außer-Kraft-Setzen des Dispositivs des Nationalen ebenso wie die utopische Öffnung der Gegenwart auf eine Weltdemokratie hin nicht erfasst werden. Deshalb werden in diesem Kapitel die Dimension des Religiösen, die im Vulkan über die Figur des Engels mit dem modernen Exil vermittelt wird, und ihre besondere Bedeutung für die in der neueren Exil-Forschung intensiv diskutierten „Fragen nach transhistorischen und transnationalen Perspektiven des Exils“" ${ }^{30}$ untersucht. Dabei eröffnen sich auch über den Roman hinausführende Einsichten in anthropologische Reflexionen des 20. Jahrhunderts ebenso wie in das vieldiskutierte Verhältnis von Säkularisierung und Religion. Der für den Roman so zentrale Vermittlungs- und Transzendierungsgedanke knüpft sich an den Engel, der die Scharnierstelle zwischen der realhistorischen Situation der Heimatlosen und der numinosen Sphäre bildet und der als angelus interpres die Funktionalisierung des Exils in göttliche Pläne offenbart. Diese beinhalten laut dem Engel der Heimatlosen „Absichten von schier unvorstellbarer Freundlichkeit“ (V 543) - eine Operation der Sinnstiftung, die nicht nur die Romanfiguren, sondern auch die Exilantinnen und Exilanten des Jahres 1939 adressiert.

Im Folgenden sollen zunächst die Gebrochenheit der Exilstruktur und das mit ihr verbundene Verlangen nach paradiesischer Einheit untersucht werden. Dabei spielen die geschichtsphilosophische Dimension des Engels und seine individualgeschichtliche Stellung zwischen Leben und Tod eine wesentliche

29 Klaus Mann, Tagebucheintrag, 24. April 1939. In: Mann, Tagebücher 1938-1939, hg. von Joachim Heimannsberg, Peter Laemmle u. Wilfried F. Schoeller, Reinbek 1995, S. 102.

30 Doerte Bischoff u. Susanne Komfort-Hein, Einleitung: Literatur und Exil. Neue Perspektiven auf eine (historische und aktuelle) Konstellation. In: Literatur und Exil. Neue Perspektiven, hg. von Doerte Bischoff u. Susanne Komfort-Hein, Berlin; Boston 2013, S. 1-19, hier S. 1. 
Rolle. Hier ist vor allem auf die prekäre Beschaffenheit dieses liminalen undstrukturell exilischen Bereichs zu verweisen, von dem aus ein Zukunftsbild entworfen wird, in dessen Fluchtpunkt weltliche Humanität und göttliches Heilsgeschehen konvergieren, der aber auch Abzweigungen in regressiv-eskapistischen Sackgassen beinhaltet. Anschließend werden konkrete Figurationen und Attribute des Engels, mit ihm assoziierte asketische Charakteristika und Praktiken sowie Schreibverfahren einer Stillstellung und archetypischen Überhöhung der Exil-Leiden in einer sakralen Ikonologie untersucht. Der Fokus liegt dabei auf Strategien der Angelisierung, die zur Aufwertung der Heimatlosen gegen die Entwürdigung ihrer Exilexistenz ins Feld geführt werden.

Zum Schluss wird mit der Initiationsszene des Engelskusses das Ethos künstlerischen Schaffens im Exil und dessen politisch-poetologischer Fond eruiert. Dabei wird nachvollzogen, wie aufgrund der rekursiven Struktur des „Exilsroman im Exilsroman“31 - poetologisch durch den Engel als Figur der Darstellung der Darstellung gestützt - die Strategien zur Aufwertung der nomadischen und ständig bedrohten Existenz auch und wesentlich auf extratextueller Ebene greifen. Der Fluchtpunkt dieser Aufwertung ist der Gedanke einer neuen Ordnung, der sich durch Klaus Manns publizistisches Schreiben zieht und im Vulkan durch den Engel vermittelt wird.

\subsection{Exil. Zwischen verlorener Staatsangehörigkeit und transnationalem Zukunftsprojekt}

Die Frage nach einer „neuen Ordnung“ war in den 1930er Jahren weit verbreitet. $^{32}$ Auch Hitler beschäftigte sich mit der Frage nach einer „Neuordnung Europas“, die seine expansive Aggressionspolitik ideell unterfüttern sollte. ${ }^{33}$ Klaus Manns Haltung zu der Frage, wie ein postfaschistischer Staat aussehen sollte, blieb zunächst auf die deutsche Perspektive beschränkt. Im Zuge seines Engagements für die Politik der Einheitsfront, in der alle antifaschistischen Kräfte ungeachtet ihrer politischen Differenzen gebündelt werden sollten, beschäftigte

31 Volz, Sehnsucht nach dem ganz anderen, S. 151.

$32 \mathrm{Vgl}$. zu den folgenden Ausführungen auch Lena Zschunke, „Leidend und liebend verwandelt sich der Mensch“. Ästhetische Strategien der Angelisierung in Klaus Manns Der Vulkan. In: Himmlisch, irdisch, höllisch. Religiöse und anthropologische Annäherungen an eine historische Ästhetik, hg. von Olivia Kobiela u. Lena Zschunke, Würzburg 2019, S. 253-291.

$33 \mathrm{Vgl}$. Birgit Kletzin, Europa aus Rasse und Raum. Die nationalsozialistische Idee der Neuen Ordnung, Münster 2000. 
Mann sich schon früh mit der Frage, was „nach dem Sturze Hitlers“34 passieren sollte, so der Titel eines Diskussionsbeitrags vom April 1939. Sein flügelübergreifendes Denken reichte so weit, dass er auch die innerdeutsche Opposition an dem geforderten Zukunftsprogramm beteiligen wollte. ${ }^{35}$ Diese an nationalstaatlichem Denken orientierte Ausrichtung prägte auch die Zeitschrift Die Sammlung (1933-1935), die Klaus Mann als Sammelbecken für alle Exilantinnen und Exilanten konzipierte. Der Fluchtpunkt, in dem sich Exilgemeinde und innerdeutsche Opposition treffen sollten, war das ideelle Konstrukt eines „anderen Deutschlands“, einer friedlichen Kulturnation:

Ebenso müssen wir klarstellen, daß es ein anderes Deutschland gibt [...]. Wir müssen wieder und wieder betonen, daß Hitler keinesfalls die deutsche Nation repräsentiert. Die Deutschen haben die Nazi-Diktatur aus Unwissenheit akzeptiert und weil sie Hitlers falschen Versprechungen glaubten [...]. [...] In der großen Tradition deutscher Kultur und geistigen Lebens finden sich keine naziähnlichen Tendenzen. ${ }^{36}$

Allerdings musste Klaus Mann eingestehen, dass die vorbildliche deutsche Kultur „[l]eidvoll-opponierend [...] diesem [nationalen, L.Z.] Begriff immer aufs intimste verbunden“"37 blieb. 1940 war seine Ernüchterung angesichts der ausbleibenden flächendeckenden Auflehnung in Deutschland so groß, dass auch das Wunschbild eines transzendenten, von den Versehrungen des Hitler-Regimes unbefleckten Deutschlands zusammenbrach: „Es gibt nur ein Deutschland, und dieses muß erst geschlagen, dann überwacht, gesäubert, erzogen, geheilt, finanziert und endlich zurück in die Gemeinschaft der zivilisierten Völker geführt werden. “38 Während sich die postulierte Überschreitung des Nationalstaats bis dahin auf Deutschland konzentrierte, erstreckt sich Klaus Manns Denken ab 1941 auf den gesamten Globus. Diese Bewegung lässt sich an der gewandelten programmatischen Ausrichtung seiner Zeitschriftenprojekte ablesen. Während Die Sammlung ein Forum für Exilantinnen und Exilanten darstellte, ist Decision. A Review of Free Culture dezidiert keine

34 Mann, Nach dem Sturze Hitlers, S. 89.

35 Vgl. Mann, Nach dem Sturze Hitlers, S. 89.

36 Klaus Mann, Ich liebe dieses Land. Gedanken in einem amerikanischen Pullman-Wagen. In: Mann, Zweimal Deutschland. Aufsätze, Reden, Kritiken 1938-1942, hg. von Uwe Naumann u. Michael Töteberg, Reinbek 1994, S. 145-158, hier S. 152.

37 Klaus Mann, Joseph Breitbach, der richtige. In: Mann, Zahnärzte und Künstler. Aufsätze, Reden, Kritiken 1933-1936, hg. von Uwe Naumann u. Michael Töteberg, Reinbek 1993, S. 159163, hier S. 162.

38 Klaus Mann, Deutschland, die Apokalypse und die konservative Revolution. In: Mann, Zweimal Deutschland. Aufsätze, Reden, Kritiken 1938-1942, hg. von Uwe Naumann u. Michael Töteberg, Reinbek 1994, S. 351-360, hier S. 359. 
Exil-Zeitschrift: „,Decision“ widmet sich nicht den Problemen des Exils, sondern den Problemen der Zivilisation - der komplexen, unteilbaren Zivilisation, die in diesem Krieg auf dem Spiel steht.“39

Zur neuen Argumentationsgröße wird in diesem zwar westlich verankerten, aber letztlich transnational ausgerichteten Denken der Mensch. „Da das Endziel unseres Feindes die Enthumanisierung des Menschen ist, muß unser allererstes Anliegen das Streben nach dem Ideal eines neuen Humanismus sein“ ${ }^{40}$, heißt es im Editorial des ersten Heftes von Decision im Januar 1941. Die „Zukunftsvisionen“ “41, denen sich Klaus Mann in seiner Zeitschrift widmete, zielten ab auf die „Zeit nach Hitlers Niederlage“42 und galten einer „New Order“43, einer neuen, freiheitlichen Ordnung. Da die umfassende Enthumanisierung durch das NS-Regime nationalstaatliche Kategorien offenkundig überschreitet, kehrt auch Klaus Mann sich von ihnen ab. Die Dimension der Zukunft, die seiner humanistischen Idee unterlegt ist, stützt sich auf eine religiöse und das heißt hier vor allem transnationale Aufladung. Auf der Basis eines Menschheitsganzen, das sich nicht in „Rassen“ “44 zerlegen lässt, nimmt Klaus Mann eine religiös durchwirkte „Sendung des Menschenlebens“ an, die das Trachten „nach einer besseren Ordnung [...] auf unserem Stern“ ${ }^{\text {45 }}$ beinhaltet.

Künstlerinnen, Künstler und Intellektuelle sind für Mann besonders gefragt, wenn es darum geht, Zukunftsvisionen in der Gegenwart zu gestalten und auf diese Weise mit Durchschlagskraft auszustatten. So ist es „die Aufgabe, der natürliche Auftrag der Intellektuellen, der freien Schriftsteller, der Gelehrten und Denker, die Struktur einer neuen Gesellschaft anschaulich zu machen und in ihren Umrissen darzustellen“ “66. In dieser Hinsicht knüpft Klaus Mann auch strukturell an die humanistische Tradition an, insbesondere an Schillers Projekt einer „ästhetischen Erziehung des Menschen“47, die durch die Kunst

39 Klaus Mann, In eigener Sache. In: Mann, Zweimal Deutschland. Aufsätze, Reden, Kritiken 1938-1942, hg. von Uwe Naumann u. Michael Töteberg, Reinbek 1994, S. 374-380, hier S. 377.

40 Klaus Mann, Decision. In: Mann, Zweimal Deutschland. Aufsätze, Reden, Kritiken 19381942, hg. von Uwe Naumann u. Michael Töteberg, Reinbek 1994, S. 235-239, hier S. 235.

41 Mann, Deutschland, die Apokalypse und die konservative Revolution, S. 351.

42 Mann, Deutschland, die Apokalypse und die konservative Revolution, S. 351.

43 Mann, Deutschland, die Apokalypse und die konservative Revolution, S. 352.

44 Klaus Mann, Wer sind wir? In: Mann, Zweimal Deutschland. Aufsätze, Reden, Kritiken 1938-1942, hg. von Uwe Naumann u. Michael Töteberg, Reinbek 1994, S. 339-347, hier S. 347.

45 Mann, Wer sind wir?, S. 347.

46 Klaus Mann, Der Staat des Menschen. In: Mann, Zweimal Deutschland. Aufsätze, Reden, Kritiken 1938-1942, hg. von Uwe Naumann u. Michael Töteberg, Reinbek 1994, S. 246-254, hier S. 249. 47 Friedrich Schiller, Über die ästhetische Erziehung des Menschen in einer Reihe von Briefen. In: Schiller, Sämtliche Werke in 5 Bänden, Bd. 5, hg. von Peter-André Alt, Albert Meier u. Wolfgang Riedel, München 2004, S. 570-669. 
vermittelt wird. Zwischen Schillers und Manns Schreiben gibt es eine Reihe von Parallelen. Sie schreiben in einer Zeit der Krise, in der sie eine fundamentale Bedrohung zivilisatorischer Errungenschaften erblicken. Für Klaus Mann ist es die „totalitäre Barbarei“ ${ }^{48}$ des Faschismus, für Friedrich Schiller die ungute Entwicklung der Französischen Revolution, die sich ihm spätestens mit dem terreur ab Juni 1794 als „Rückfall in die Barbarei“ darstellte, „in dem das Projekt Aufklärung zusammenbrach“"49.

Schiller und Mann sehen angesichts der Bedrohung des aufgeklärten, zivilisierten Denkens die dringende Notwendigkeit einer Humanisierung des Menschen. Beide wenden sich für die Umsetzung dieses Projekts nicht der politischen Intervention $\mathrm{zu}$, sondern nehmen den scheinbaren Umweg über eine anthropologisch fundierte Kunst. So schreibt Schiller, man müsse „um jenes politische Problem in der Erfahrung zu lösen, durch das ästhetische den Weg nehmen [...], weil es die Schönheit ist, durch welche man zu der Freiheit wandert"50. Schiller und Mann stimmen darin überein, dass eine ästhetische Erziehung der oder des Einzelnen den „inhumanen Zustand der Gesellschaft auf kontinuierliche und humane Weise verändern und in sein Gegenteil verkehren“51 soll. Auch der Gedanke, dass der Kunst neben ihrer äquilibrierenden Wirkung auf einander widerstreitende Triebe - eine herausragende Bedeutung für die Veranschaulichung einer neuen Ordnung zukommt, geht auf Schiller zurück. Die Gesellschaft bedarf seiner Ansicht nach für ihren Übergang zu jenem (unsinnlichen) Ideal eines „dritten Charakter[s]“, der „zu einem sinnlichen Pfand der unsichtbaren Sittlichkeit diente“ ${ }^{\text {52 }}$. Die Aufwertung der ästhetischen Fiktion hat ihr Pendant in der von Klaus Mann ausgemachten Bedeutung der geistigen Zunft, die aufgefordert ist, das Ideal einer neuen Weltordnung zu veranschaulichen. Strukturell entspricht dieser „dritte Charakter“ dem Engel, der sinnlich für eine neue Ordnung einsteht, die noch nicht verwirklicht ist.

In dieser Rolle prägt er den Vulkan entscheidend, der sich als expliziter „Emigrantenroman“ auf der Schnittstelle zwischen dem gegenwärtigen Exil und einer noch nicht verwirklichten neuen Ordnung befindet. Mit seinen Qualitäten als Medium der Darstellung des Undarstellbaren und doppelzeitliche,

48 Mann, Decision, S. 235.

49 Wolfgang Riedel, Kommentar [Ästhetische Abhandlungen]. In: Schiller, Sämtliche Werke in fünf Bänden, Bd 5, hg. von Peter-André Alt, Albert Meier u. Wolfgang Riedel, München 2004, S. 1151-1341, hier S. 1221.

50 Schiller, Über die ästhetische Erziehung des Menschen, S. 573.

51 Yvonne Ehrenspeck, Die Idee der Humanisierung des Menschen im Medium ästhetischer Bildung bei Friedrich Schiller und Johann Friedrich Herbart. In: Bildung: Angebot oder Zumutung, hg. von Yvonne Ehrenspeck, Gerhard de Haan u. Felicitas Thiel, Wiesbaden 2008, S. 75-93, hier S. 75. 52 Schiller, Über die ästhetische Erziehung, S. 576. 
nämlich exilisch-elysische Figur birgt der Engel eine spezifische Potenz für die Veranschaulichung transzendenter Erfahrungen im Exil und kann zugleich eine zukünftige Fülle jenseits der geschichtlichen Zeit sichtbar machen.

\subsection{Im Exil und darüber hinaus: Engel in Der Vulkan (1939)}

Seine „grosse Komposition aus Emigranten-Schicksalen“" 53 schrieb Klaus Mann zwischen Herbst 1937 und Frühling 1939, wobei sich die erzählte Zeit der Erzählzeit immer weiter annähert. Vom 15. April 1933 bis zum 1. Januar 1939 skizziert der Vulkan die eskalierende weltpolitische Lage. Die Anzahl der Flüchtlinge wächst, während die Aufnahmebereitschaft anderer Länder sinkt:

Ein Strom von Flüchtlingen ergießt sich aus dem gemarterten Land [Österreich, L.Z.]: wohin mit ihnen? Wer nimmt sie auf? ... Manche Züge, voll mit Menschen, die sich schon in Sicherheit wähnten, mußten an den Grenzen wieder umkehren: das Nachbarland wollte die Unseligen nicht. Sie bringen Unglück, und sie fressen uns arm - dies war das Empfinden der guten Nachbarn. „Weg mit euch!“ riefen sie und verscheuchten die Emigranten wie böse Geister. „Sucht euch ein anderes Asyl! Nicht bei uns! Ihr verpestet die Luft, die ihr atmet!“ - Wie viel Tränen flossen da, an der Grenzstation! Wie viel Schreie - Männer-, Frauen- und Kinder-Schreie, ein Konzert von schrillen Dissonanzen, eine Symphonie der Qual! Manche warfen sich vor den Zug: lieber sich von seinen Rädern zermalmen lassen, als zurückkehren in die Heimat, die Hölle.

(V 503)

Wucht, Unkontrollierbarkeit und physisches Vernichtungspotential, die von dem NS-Regime ausgehen, versinnbildlicht der titelgebende Vulkan. Wer „im Zeichen des Vulkans“ lebt, schreibt Klaus Mann im Wendepunkt, hat stets „die Unabwendbarkeit, die Unentrinnbarkeit der Explosion“ “54 im Nacken. Vor dieser Bedrohungskulisse entfaltet der Vulkan einen polyperspektivischen Ausblick auf die Schicksale von Exilantinnen und Exilanten verschiedenster Couleur, deren Wege auf vielfache Weise miteinander verflochten sind.

$\mathrm{Zu}$ den Protagonistinnen und Protagonisten zählen Mutter Schwalbe, die in Berlin ein kleines Restaurant betrieb, in dem ,über Marxismus, atonale Musik und Psychoanalyse“ (V 17) diskutiert wurde, die Schauspielerin Marion von Kammer, „ebenso ungeschickt wie enthusiastisch“ (V 22), der begabte, aber etwas selbstgefällige Schriftsteller Martin Korella und sein empfindsamer Bewunderer, der Philosoph David Deutsch. Sie finden sich im April 1933 in Paris zusammen und bilden

53 Klaus Mann, Tagebucheintrag, 20. August 1936. In: Mann, Tagebücher 1936-1937, hg. von Joachim Heimannsberg, Peter Laemmle u. Wilfried F. Schoeller, Reinbek 1995, S. 69-70, hier S. 69.

54 Mann, Der Wendepunkt, S. 509. 
gemeinsam mit dem Maler Professor Samuel, dem Lebenskünstler Bobby Sedelmayer und dem Mäzen und „,rote[n] Millionär““ (V 37) Siegfried Bernheim eine Exilgemeinschaft. $\mathrm{Zu}$ ihnen gesellen sich Marcel Poiret, Teil eines Künstlerkollektivs, das „einen konsequenten, aggressiven Marxismus mit einem extremen Romantizismus zu vereinigen sucht[e]“ (V 23/24), und Kikjou, der laut Marion „,zu diesen Jungens [gehört], wie man sie in Paris manchmal trifft, die alle Sprachen können und gar keine““ (V 29). Neben der intellektuellen Bohème mit ihren „Piqueuren, Sodomiter[n] und Engelseher[n] "55 werden auch die Schicksale der Genossen Theo Hummler und Dr. Mathes ebenso wie die der Arbeiter Ernst und Hans Schütte beleuchtet. Im Gegensatz zu der dezidierten Aversion von Bohème und linken Aktivistinnen und Aktivisten gegenüber dem Nationalsozialismus ist Professor Benjamin Abel laut Charakterisierung seines ehemaligen Studenten David „,der unpolitische, antirevolutionäre Deutsche par excellence““ (V 106). Er wird durch seine jüdische Herkunft zur Emigration gezwungen, während die adelige MarieLuise von Kammer Deutschland verlässt, weil sie die Nazis für „,gemeine Plebejer““ (V 73) hält.

Marion von Kammer, Martin Korella, Marcel Poiret, David Deutsch und Kikjou, die im Fokus des Romangeschehens stehen, zeichnet eine Unruhe aus, die durch ihre Emigration verstärkt, aber nicht ursächlich hervorgerufen wurde. So wird der leidvolle Umstand des Heimatverlusts immer wieder überblendet mit Bildern und Artikulationen eines übergeordneten Gefühls von Verwaisung, Entfremdung und Orientierungslosigkeit, einer kollektiven Exilierung, die aus dem „sozialen und geistigen Vakuum“56 der Zwischenkriegszeit herrührt. Die Fluchtbewegungen der Figuren zielen daher nicht nur realgeographisch weg von dem „kranke[n] Kontinent“ (V 505) Europa, sondern sind geopoetisch aufgeladen und von der Sehnsucht nach einem transzendent überhöhten Ursprungszustand getragen, der Ruhe, Unverdorbenheit und Frieden verspricht. Die Neigung zur Regression in künstliche Paradiesattrappen birgt jedoch in der Abkehr von zivilisatorischen Errungenschaften die Gefahr des apokalyptischen Umschlags:

Die Zivilisation - im Stich gelassen, aufgegeben von ihren klügsten, aufmerksamsten Söhnen - scheint nach dem eigenen Untergang zu lechzen. Lange genug hat sie sich üppig entfaltet, jetzt aber will sie heim, zurück, in den Urwald -: mit ihren eigenen Mitteln, mit dem Raffinement ihrer triumphierenden Technik hebt sie sich selber auf. Noch einmal entfaltet sie sich aufs eindrucksvollste, ihre Apokalypse ist pittoresk - großes Schauspiel, glänzend inszeniert -: in schaurig-imposanten Bildern führt sie sich zu Ende. ,Der totale Krieg‘: blutrünstige Intellektuelle, späte Erben des abendländischen Geistes -

55 Thomas Mann, Brief an Klaus Mann, 22. Juli 1939. In: K. Mann, Briefe und Antworten 19221949, hg. von Martin Gregor-Dellin, Reinbek 1991, S. 388-391, hier S. 389.

56 Mann, Der Wendepunkt, S. 591. 
hysterisch entartet, völlig ruchlos geworden - haben ihn eifrig genug propagiert, seine stählern vernichtende Schönheit in schrillen Tönen besungen.

(V 484)

Der Hang zur „katastrophischen Rückbildung“57 erscheint als Ausdruck eines lagerübergreifenden Zeitgeists. Entsprechend betrifft er im Vulkan nicht nur die Trägerinnen und Träger des Nationalsozialismus, sondern ebenso die unterordnungswilligen Exilantinnen und Exilanten mit ihrer Sehnsucht nach ganzheitlichen Ordnungsentwürfen. ${ }^{58}$ Gerade die Intellektuellen, die „klügsten, aufmerksamsten Söhne“, sind davor nicht gefeit. Die Tendenz, aus einer ihrer selbst überdrüssigen Zivilisiert- und Individuiertheit in den apokalyptischen Rausch der Barbarei zu regredieren, zeigt sich daher nicht nur im Extrem der nationalsozialistischen Todeshetzen. Sie wird auch in dem sacrificium intellectus von Figuren wie dem Schriftsteller Marcel Poiret deutlich, der fordert: „Wir müssen eine neue Unschuld lernen. Zu der kommen wir nicht durch Worte; nur durch die Tat. Die großen Worte hängen an uns wie Schmutz, machen unsere Stirnen klebrig und unsre Hände. Nur eine Flüssigkeit wäscht dies ab: Blut. [...] Wir sollen töten und leiden; nicht mehr reden und schreiben." (V 257)

Im Zuge seines Strebens nach Gewalt, Künstlichkeit und Unschuld, den „drei großen Stimulantia der Erschöpften“59, wie Nietzsche weiß, opfert Marcel sich auf dem Schlachtfeld des Spanischen Bürgerkriegs. Erst in seinem Tod, der Wort und Tat zusammenführt, wird die ersehnte Vereinigung mit der Masse möglich (vgl. V 377). Zu den fatalen Folgen, die die Versuche nach sich ziehen, den gesellschaftlichen und biographischen Brüchen durch die Flucht in vermeintlich unberührte Oasen zu entgehen, tritt die Bedrohung, die in dem prekären juridischen Status der Exilantinnen und Exilanten liegt. Denn die sich ausdehnenden Räume unsicheren Rechts, in der sich die Staatenlosen in einer „Zone der Ununterschiedenheit und des Übergangs zwischen Tier und Mensch,

57 Theodor W. Adorno, Minima Moralia. Reflexionen aus dem beschädigten Leben. Gesammelte Schriften, Bd. 4, Frankfurt am Main 1980, S. 270.

58 Vgl. Arwed Schmidt, Exilwelten der 30er Jahre. Untersuchungen zu Klaus Manns Emigrationsromanen ,Flucht in den Norden“ und ,Der Vulkan. Roman unter Emigranten', Würzburg 2003, S. 30. Zu dieser Gefahr im Exil vgl. Doerte Bischoff: „Diese Konstellation [in Werfels Jacobowsky und der Oberst, L.Z.] demonstriert noch einmal in aller Deutlichkeit, dass ein Exilbegriff, der auf eine verloren gegangene Präsenz bezogen bleibt, an dem Diskursmuster ausschließender Identifizierung und mythischer Selbstbegründung partizipiert, das auch die nationalsozialistische Heimatideologie charakterisiert“ (Doerte Bischoff, Exil und Interkulturalität - Positionen und Lektüren. In: Handbuch der deutschsprachigen Exilliteratur. Von Heinrich Heine bis Herta Müller, hg. von Gerhild Rochus u. Bettina Bannasch, Berlin 2013, S. 97-119, hier S. 114).

59 Friedrich Nietzsche, Der Fall Wagner. In: Nietzsche, Werke in drei Bänden, Bd. 2, hg. von Karl Schlechta, München 1954, S. 901-939, hier S. 913. 
zwischen Natur und Kultur" ${ }^{60}$ befinden, beinhalten konkretes physisches Vernichtungspotential. Das Menschliche, dessen beobachtete Auflösung in den vorigen Kapiteln immer wieder Thema war, steht im Faschismus auf existentielle Weise auf dem Spiel.

In dieser Situation tritt der Engel im Vulkan als Figur des Exils in Erscheinung, die den von Tod und Würdelosigkeit bedrohten Menschen aufwertet und sakralisiert. So wird der Engel als Widerpart des Tiers mobilisiert, um die rhetorischen Praktiken der Animalisierung, die die nationalsozialistische Ausbürgerungspolitik flankierten und stützten, ${ }^{61} \mathrm{zu}$ parieren und in ihr Gegenteil zu verkehren. Über das engelsgleiche Leben wird das Nichtmenschliche positiv besetzt und die biologistische Metaphorik überschritten. ${ }^{62}$ Neben der angelomorphen Zeichnung der Protagonistinnen und Protagonisten ist der gesamte Roman über das mit dem bios angelikos verbundene Prinzip des Umschlags von physischem Mangel in geistigen Reichtum organisiert. Auf diese Weise wird der strukturelle Mangel des Exils, den die Romanfiguren in Form des Verlusts von Heimat und Staatsangehörigkeit sowie der Knappheit von Nahrung und Geld erleiden müssen, durch seine spezifische Darstellung in ästhetisch-überirdische Fülle transformiert. Zudem wird über diesen ins Numinose erweiterten Handlungsrahmen eine neue, von Gott sanktionierte Ordnung des Menschlichen entworfen. So wird der verheerende Realitätsbefund von wachsendem Elend und einem drohenden Krieg durch unmittelbare Einbrüche des Transzendenten überschritten, die einen olympischen Blickpunkt und heilsgeschichtliche Fülle gegen Chaos, Zersplitterung und Orientierungslosigkeit der Weltzeit geltend machen.

60 Giorgio Agamben, Homo sacer. Die Souveränität der Macht und das nackte Leben, Frankfurt am Main 2002, S. 119.

61 Vgl. Carla Swiderski, Über das „Quallenschwein“. Mensch/Tier-Konstellationen in Oskar Maria Grafs Exilroman Die Flucht ins Mittelmäßige. In: Exil Lektüren. Studien zu Literatur und Theorie, hg. von Doerte Bischoff, Miriam N. Reinhard u. Claudia Röser, Berlin 2014, S. 92-99, hier S. 92-93. Zu der Tiermetaphorik bei Joseph Goebbels vgl. Claus-Ekkehard Bärsch, Der junge Goebbels. Erlösung und Vernichtung, München 2004, S. 36-37. Antje Kapust spricht von der ,außerordentliche[n] Rolle als stabilisierende und stimulierende Funktion der Dehumanisierung“, die „die Stereotypisierung des Feindes in der Tiermetaphorik“ in der Moderne einnehme (Antje Kapust, Der Krieg und der Ausfall der Sprache, München 2004, S. 330-331). Dabei wurde die „Tierwelt [...] von der nationalsozialistischen doxa in die unsichtbaren Bereiche der Parasitologie und Bakteriologie ausgedehnt, in einer Validierung aller Fantasmen von Beschmutzung und Schädigung der ,Reinrassigkeit““ (Régine-Mihal Friedman, Jüdische Charaktere/Nazi-Schauspieler. Zwischen Mimikry und Mimesis. In: Körper im Nationalsozialismus. Bilder und Praxen, hg. von Paula Diehl, München 2006, S. 91-105, hier S. 92).

62 Zum bios angelikos vgl. Kapitel 2.1 dieser Studie. 


\subsubsection{Von Exilzuständen und der Flucht in künstliche Paradiese}

Den Hebel für diese Umschlagsbewegung bildet der Gedanke, dass das Exil eine Prüfung für den Menschen bedeutet. Im Vulkan gibt es drei Reaktionen auf diese Prüfung: Einige der Betroffenen „vereinsamten, wurden asozial, weil sie an nichts denken, über nichts reden konnten, was nicht das eigene Elend betraf“ (V 472). Andere flüchten sich in künstliche Paradiese, die letztlich in den Tod führen. Die Feuertaufe des Exils bestehen nur jene, die entschlossener, empfindsamer und damit menschlicher werden: „Das Exil - die harte Schule, durch die sie gingen - hatte sie zu Menschen geformt.“ (V 473) ${ }^{63}$ Dieses Menschsein allerdings ist fundamental bedroht - nicht nur durch den erlahmenden Willen, der in der „harten Schule“ des Exils so schnell gebrochen wird. In dem fortwährenden Ausnahmezustand der Suspension des Rechts, der sich in Form des Lagers materialisiert, ist der Flüchtling nach Agamben auf den nackten Leib reduziertes Freiwild, ein homo sacer, der durch die „Straflosigkeit seiner Tötung und d[as] Verbot der Opferung ${ }^{\text {"64 }}$ charakterisiert ist. Ein Mensch kann als solcher nur dann bestehen, wenn er die entsprechenden Papiere hat. Im Wendepunkt resümiert Klaus Mann: „Ohne Paß kann der Mensch nicht leben. Das scheinbar unbedeutende Dokument ist in Wahrheit beinah ebenso kostbar wie der Schatten,

63 Der Gedanke des Exils als einer „harten Schule“ findet sich wiederholt bei Klaus Mann, etwa in seinem „Appell an die Freunde“: „Versucht die Emigration als das zu verstehen, was sie für den geistigen Menschen vor allem ist: als ein geistiges Schicksal; als eine geistige Aufgabe; als eine harte Schule, aus der jeder, der sie besteht, härter, erfahrener, vielleicht besser hervorgehen wird, als er vorher gewesen ist. Diese harte Schule, diese große Vereinsamung haben wir uns selber auferlegt - nicht aus Leichtsinn, auch nicht aus dünkelhaftem Trotz, sondern um unsere Menschenwürde zu wahren und weil unsere Liebe zu Deutschland die Erniedrigung Deutschlands nicht erträgt; weil unsere Liebe zu Europa uns empfindlich macht für die Gefahr, die ein solches Deutschland für den Frieden der Völker bedeutet“ (Klaus Mann, Appell an die Freunde. In: Mann, Zahnärzte und Künstler. Aufsätze, Reden, Kritiken 19331936, hg. von Uwe Naumann u. Michael Töteberg, Reinbek 1993, S. 322-327, hier S. 326). Eine ähnliche Einteilung findet sich in der Typologie des Exils, die Lion Feuchtwanger in seinem Roman Exil (1940) entwirft, wobei hier eine pessimistischere Einschätzung vorherrscht: „Den wenigsten bekamen die Leiden, die sie durchzumachen hatten. Denn es ist so, daß Leiden nur den Starken stärker, den Schwachen aber schwächer macht. Das alte Deutsch kennt für den Vertriebenen, für den Exilanten, zwei Worte: das Wort ,Recke', das nichts anderes bedeutet als eben Vertriebener, Geächteter, und das Wort ,Elend', das wiederum den Mann ohne Land, den aus dem Land Gestoßenen bedeutet. So bezeichnet die Weisheit der deutschen Sprache die beiden Pole, die das Wesen des Emigranten begrenzen. Unter den deutschen Emigranten wurden die meisten Elende und nicht sehr viele Recken [...].“ (Lion Feuchtwanger, Exil, Berlin 2004, S. 135).

64 Agamben, Homo sacer, S. 83. 
dessen Wert der arme Peter Schlemihl erst so recht begriff, als er sich seiner leichtfertigerweise entäußert hatte. “65

Die existentielle Schutzlosigkeit, die dieser Verlust bedeutet, zeigt sich im Vulkan in der Szene der Verhaftung des passlosen Kommunisten Ernst Schütte durch einen Vertreter der Fremdenpolizei, dem „Inferno der Heimatlosen“66.

\begin{abstract}
Vor ihm stand ein Herr in dunklem Überzieher, mit steifem schwarzen Hut, einem hohen, blendend weißen Kragen und schwarzen, blankgewichsten Stiefeln, die unter hellen Beinkleidern sichtbar wurden. [...] Der Herr musterte, mit einem kalten feindlichen Blick durch den Zwicker, den nackten jungen Menschen, der ihm gegenüber stand. Die korrekte Figur des Herrn drückte von den Stiefelspitzen bis zum Scheitel Mißbilligung aus. [...] Der Herr betrachtete, ausführlich und unbarmherzig, diese frierende Nacktheit. Er schien die Rippen zählen zu wollen, die sich abzeichneten unter der gespannten Haut. Er mißbilligte das zerzauste Haar und das verstörte Gesicht des jungen Menschen; er nahm Anstoß an den gar zu sichtbaren Rippen, dem totalen Mangel an Bauch -: Menschen, die in einer anständigen Beziehung zur bürgerlichen Weltordnung leben, müssen einen etwas gepolsterten Bauch zeigen -, und er empfand Ekel sowohl als Entrüstung angesichts der provokanten Entblößung des Geschlechts.

(V 209)
\end{abstract}

Dem Herrn steht der Mensch gegenüber, den Insignien bürgerlicher Ordnung und Saturiertheit der nackte, frierende Exilant, der der Willkür ordnungspolitischer Instanzen ausgeliefert ist. Der Verweis auf die „bürgerliche Weltordnung“ zu der der magere Mensch in einem zwielichtigen Verhältnis steht, ruft die ordnungsdestabilisierende Komponente des asketischen Lebens auf. Die bürgerliche Weltordnung ist die nationalstaatliche Ordnung, und der bloße Mensch fällt durch ihr Raster. Obwohl die existentielle Not der Grund für die sichtbaren Rippen ist, liegt in dieser Szene mehr - die Nacktheit, ikonographisch seit der Antike mit Tugendhaftigkeit verbunden und ein zentrales Attribut des gekreuzigten Leib Christi, ${ }^{67}$ steht hier für die Kategorie universaler Menschlichkeit gegen die Gewaltförmigkeit nationalstaatlicher Ordnung.

Das fehlende Papier, das die Grundlage dieser Szene bildet, hat im Exil eine ambivalente Stellung. Einerseits tritt der Mensch hinter Dokumente zurück, die

65 Mann, Der Wendepunkt, S. 420.

66 Erika Mann u. Klaus Mann, Europa ist eng. In: K. u. E. Mann, Escape to Life. Deutsche Kultur im Exil, München 1991, S. 233-246, hier S. 235.

67 Zur Antike vgl. Cornelia Logemann, Allegorie im Atelier. Körperbilder in der amerikanischen Skulptur nach 1900. In: Körper-Ästhetiken. Allegorische Verkörperungen als ästhetisches Prinzip, hg. von Cornelia Logemann, Miriam Oesterreich u. Julia Rüthemann, Bielefeld 2013, S. 61-90, hier S. 70. Zum gekreuzigten Leib Christi vgl. Gerhard Marcel Martin, Der nackte Leib Christi. In: „Leiblichkeit ist das Ende der Werke Gottes“. Körper - Leib - Praktische Theologie, hg. von Michael Klessmann u. Irmhild Liebau, Göttingen 1997, S. 101-111. 
über Ausreise- und Aufenthaltsmöglichkeiten entscheiden. ${ }^{68}$ „Ein Transit-Visum durch Belgien wird zum großen Problem, ein Affidavit für die Vereinigten Staaten zum erregenden Thema, die Arbeits-Erlaubnis in der Schweiz zur ersehnten Gabe des Himmels“ (V 471/472), wie es im Vulkan heißt. Andererseits steht das Papier in Form der Repräsentation der Erfahrung für die Exilierte oder den Exilierten ein und ermöglicht ihr oder ihm eine narrative Verarbeitung und identitäre Neumodellierung. So liegt nach Elisabeth Bronfen in der schreibenden Selbstvergewisserung des exilierten Subjekts eine befreiende, ja lebenswichtige Tätigkeit. In ihrem Aufsatz „Exil in der Literatur“ (1993) stellt sie die These auf, dass auf die Entwurzelungserfahrung des Exils, aus der eine „Weltlosigkeit“69 resultiere, mit einem neuen Selbstentwurf reagiert und das zerstörte Leben in einem kohärenten Narrativ zusammengefügt werden müsse. In diesen Repräsentationen des Exilerlebnisses präge die traumatische Entortungserfahrung nicht nur den Inhalt, sondern konstituiere allererst das Repräsentationssystem und damit den Modus der Darstellung. ${ }^{70}$ Mit der Verschiebung, die dadurch in der konstruierten Realität gegenüber dem unmittelbaren Erleben und Erleiden des Exils entsteht, greift Elisabeth Bronfen ein Strukturmuster auf, das im Zusammenhang mit dem Engel in Form des sinngenerierenden Bruchs, der seiner Repräsentation eingeschrieben ist, bereits thematisiert wurde. Als Figur zwischen und über den Zeiten macht er das zeitlich wie räumlich Abwesende in der Gegenwart sichtbar. Die strukturelle Affinität zur Literatur des Exils ergibt sich aus jener „paradoxe[n] Verschränkung von Entzug und Vergegenwärtigung““71, die nach Bernhard Greiner Exilliteratur kennzeichnet und die der Engel in seinem Sichtbarmachen von etwas Abwesendem verspricht.

Darin liegt ein Moment des Unheimlichen. Mit Freud versteht Elisabeth Bronfen es als einer Ambivalenz oder Unsicherheit erwachsendes Gefühl von Deplatzierung und identitärer Destabilisierung und erklärt es zu dem zentralen Charakteristikum der Exilerfahrung und ihrer Narration. ${ }^{72}$ Das Fremdwerden der Heimat als das prototypische Unheimliche des Exils beschreibt Klaus Mann im Wendepunkt: „Alles, was mit Deutschland zu tun hatte, wurde unheimlich, beängstigend“73, die alte Heimat ist eine „entfremdete, gräßlich gewordene“74,

$68 \mathrm{Vgl}$. Bronfen, Exil in der Literatur, S. 169.

69 Bronfen, Exil in der Literatur, S. 170.

$70 \mathrm{Vgl}$. Bronfen, Exil in der Literatur, S. 168.

71 Greiner, Re-Präsentation, S. 162.

$72 \mathrm{Vgl}$. Bronfen, Exil in der Literatur, S. 171.

73 Mann, Der Wendepunkt, S. 417.

74 Mann, Der Wendepunkt, S. 419. 
Deutschland „die Hölle, das unbetretbare Gebiet, die verfluchte Zone“75. Dennoch kehren die Ausgestoßenen im Vulkan immer wieder dorthin zurück, gedanklich oder in Träumen, die „halb Alpträume, halb Wunschträume“ (V 321) sind. In ihrer Entortung sind auch die Exilierten selbst unheimlich. Zwischen Leben und Tod stehend werden sie zu „böse[n] Geister“ (V 503), die niemand aufnehmen will.

Diesen Grenzbereich macht wie bei Benjamin der Engel als nichtmenschliche Figur anschaulich, die zwischen Fassbarem und Unfassbarem, Vertrautem und Fremdem, medialen und personalen Anteilen schwankt. Der Engel der Heimatlosen, der Kikjou erscheint, ist entsprechend eine exemplarische Figuration des Unheimlichen und Ambivalenten, er ist „,[d]er Dämon der Entwurzelungs-Neurose, der Schutzpatron der Expatriierten, der Tröster, der Spötter, der FluchSpendende, der Segen-Spendende“"76. Da der Engel mit einem örtlich wie zeitlich liminalen Raum verknüpft ist, wundert es nicht, dass die Engelbilder und -erscheinungen im Vulkan gehäuft in heterotopischen Orten wie dem gefängnisartigen Entzugssanatorium oder den klosterähnlichen Zellen Kikjous auftreten. Den sogenannten Heterotopien eignet nach Foucault in ihrer doppelten Eigenschaft von Verbindung und Widerspruch zu den umgebenden Räumen ein kontrafaktisches Moment. Damit wohnt ihnen macht- und kulturdiagnostisches Potential inne. ${ }^{77}$ Dies ist insofern für den Vulkan bedeutsam, als das Exil in dem Roman nicht bloß als soziale Realität einzelner Figuren erscheint, sondern - wie bei Rilke und Benjamin - gekoppelt ist an eine umfassende Epochendiagnose.

So liegt eine weitere Ambivalenz des Exils im Vulkan in der dem abendländischen Exiltopos eingeschriebenen Spannung zwischen der realen Entortungser fahrung, die biographisch-historisch verbürgt ist, und metaphorischen Überformungen, die sich von dem konkreten Erleben lösen und mit dem Exil als Bild für Subjektwerdung, Künstlertum oder Spracherwerb operieren. ${ }^{78}$ Der Versuch, Exilliteratur historisch $\mathrm{zu}$ verorten, hat es mit drei Ebenen $\mathrm{zu}$ tun: dem radikal indi viduellen Erleben, der prototypischen Entortungserfahrung der Moderne und der Enthistorisierung westlicher Mythopoetik mit der Vertreibung aus dem Paradies als primordialem Narrativ. ${ }^{79}$ Die Verquickung dieser drei Momente ist konstitutiv

75 Mann, Der Wendepunkt, S. 417.

76 Mann, Der Wendepunkt, S. 527.

77 Vgl. Michel Foucault, Von anderen Räumen. In: Foucault, Dits et Ecrits. Schriften, Bd. 4, hg. von Daniel Defert u. François Ewald, Frankfurt am Main 2005, S. 931-942, hier S. 935.

78 Vgl. Bronfen, Exil in der Literatur, S. 176 sowie Rolf J. Goebel, Großstadterfahrung und das Exil in der Moderne. In: Benjamin und das Exil, hg. v. Bernd Witte, Würzburg 2006, S. 36-43, hier S. 36. Diese Mehrfachkodierung des Exilbegriffs und seine Verknüpfung mit der Künstlerthematik findet sich prominent auch in Klaus Manns Tschaikowsky-Roman Symphonie Pathétique (1935).

79 Vgl. Bronfen, Exil in der Literatur, S. 173-174. 
für den Vulkan. Die metonymische Austauschbarkeit der paradiesischen Signifikanten Heimatstadt, Eltern/Mutter, Kindheit, Krankheit/Tod, unberührte Natur und Drogen verweist auf ein umfassendes Verlustempfinden, das in dem konkreten Exilzustand nicht aufgeht, sondern eben jenen metaphorischen Überhang in sich begreift, der auf reale wie imaginäre Sehnsuchtsorte projiziert wird. Trügerisch sind sie allesamt.

Mit diesen Orten verbindet sich die Utopie adamitischer Ursprünglichkeit, in dessen Imagination sich die Figuren aufgrund der Unerträglichkeit der realen entmenschlichten Räume fliehen. David, dessen „Position der Verinnerlichung [um]schlägt [...] in eine für die Nazizeit bezeichnende hysterische Verherrlichung der einfachen Arbeit“ ${ }^{* 00}$, ersehnt die Überwindung seiner intellektuellen Rastlosigkeit „,[i]rgendwo, in einer wilden, reinen Landschaft - in einer Luft, die noch nicht vergiftet ist vom Lärm der Propaganda, von den Lügen der Politik““ (V 483). Er träumt „,von Urwäldern, oder grenzenlosen Prärien, von Steppen oder Gebirgen““ (V 483). Eine realgeographische Paradies-Chimäre stellt die Insel Mallorca dar, dort lebt „,man wie in Gottes Schoß““ (V 266). Vor idyllischer Kulisse verbringt der Künstlerund Intellektuellenkreis um den Bankier Siegfried Bernheim sorglose Tage in einer Fabelwelt. Allerdings muss auf dieser „,Insel der Seligen““ (V 258) das Geschehen in der Welt fortwährend verdrängt werden. Gespräche über Politik werden vermieden, Bombenexplosionen als Kindereien abgetan. Doch irgendwann kippt auch dieses Paradies: „Die Hölle ist losgelassen; tausend Teufel präsentieren sich in den kleidsamen Uniformen römischer Faschisten, oder in der korrekten Tracht preußischer Beamter und sächsischer Geheimagenten.“ (V 276/277)

In allen diesen Formen der Realitätsverweigerung versuchen die Figuren, einer zerfallenden Zivilisation in ein unberührtes Paradies $\mathrm{zu}$ entfliehen, das aber als artifizielles Konstrukt keinerlei Tragfähigkeit zu entfalten vermag und dessen Untergrund sich im Fall von Martins Drogenkonsum als tödlicher Treibsand erweist. Die Sehnsucht ist unbestimmt und gerade deshalb so anfällig für falsche Erfüllung. So sinniert Martin unmittelbar vor der als Teufelspakt inszenierten Begegnung mit dem Drogendealer Pépé:

„Es ist vielleicht gar nicht Kikjou, nach dem ich mich sehne. Ich sehne mich nach Berlin. Ich habe Heimweh nach den Straßen von Berlin, nach ein paar Lokalen und ein paar Menschen, und vielleicht sogar nach den alten Korellas ...“ [...] „Nein“, beschloß er dann wieder, „in Berlin möchte ich gar nicht sein. Es ist gräßlich dort. Ich bin froh, daß ich diese Stadt nicht mehr sehen muß. Heimweh nach der Stadt habe ich sicher nicht. Es ist die eigene Kindheit, nach der ich Heimweh habe.“

(V 91/92)

80 Schmidt, Exilwelten der 30er Jahre, S. 194. 
Eine besonders anziehende Kindheitserinnerung sind für Martin seine Nieren-Koliken, deren Schmerzen er absichtlich übertrieb, einerseits um die mütterliche Fürsorge zu steigern, andererseits wegen der schmerzlindernden und traumfördernden Injektionen, die er von seinem Hausarzt erhielt. An diese nostalgische Reminiszenz schließt sich der erste Drogenkonsum an, der wiederum die erwünschte Kindheitswirkung hat: „,So wohlig war mir nicht mehr zu Mute - seit wann? Seit mir der Onkel Doktor Injektionen gegen Nieren-Kolik verabreichte.““ (V 98) Der Verlust der mütterlichen Bindung stellt einen klassischen psychoanalytischen Exiltopos dar. Die Sehnsucht nach ihr erscheint als regressiv-narzisstisches Begehren, ebenso Martins Affinität zu Kikjou, dessen anmutige Kindlichkeit ihn ,als Widerschein der eigenen paradiesischen Kindheit“81 fesselt.

Mit Freuds These, dass „alle organischen Triebe konservativ, historisch erworben und auf Regression, Wiederherstellung von Früherem, gerichtet sind“ ${ }^{82}$, lassen sich die morphinösen Dämmerungszustände als Regress in einen autoerotischen Urgrund verstehen. Seit der Romantik dient der Drogenkonsum neben einer offenbarungsartigen Bewusstseinsweitung immer auch der Heilung von Verletzungen, die die Zivilisation dem Menschen zufügt. ${ }^{83}$ Allerdings kippt im Vulkan auch dieser durch „la chose infernale“ (V 148) erzeugte paradiesische Zustand der Gegenwartsentrücktheit und des Friedens in sein Gegenteil: „Als Martin erwachte, war es später Nachmittag. Seine erste Empfindung war: Ich bin in der Hölle. Solche Zustände kommen nur in der Hölle vor ...“ (V 248) Die eskapistische Dimension dieser trügerischen Sehnsuchtsorte wird von Marion angeprangert: „,Es [der Glaube an den Sieg, L.Z.] ist immer noch besser als der billige Trost in den künstlichen Paradiesen. Das ist etwas für ausgediente Fliegeroffiziere, die ErsatzSensationen brauchen, oder für bourgeoise Damen, die in ihrer Ehe unbefriedigt bleiben. Es ist so feige, so langweilig, so kleinbürgerlich!““ (V 255)

Im Entzugssanatorium verstellen nicht nur rauschhafte Zustände, sondern auch die Dichtung, der Schlaf und die Engel die Realität. So wird die Verführung einer morbiden Dichtung explizit mit der Verführung einer die Realität ausblendenden Droge gleichgesetzt: „Nun griff Martin nach ihm [dem Gedichtband, L.Z.], mit der gleichen gierigen und etwas schuldbewußten Geste, mit der er sonst nach der Spritze langte.“ (V 244) Martin liest die letzten zwei Strophen des Gedichts Sieh die Sterne, die Fänge von Gottfried Benn, dessen Urheber,

\footnotetext{
81 Schmidt, Exilwelten der 30er Jahre, S. 179.
}

82 Sigmund Freud, Jenseits des Lustprinzips. In: Freud, Gesammelte Werke, Bd. 13, hg. von Anna Freud, E. Bibring, W. Hoffer, E. Kris u. O. Isakower, London 1940, S. 3-69, hier S. 39.

83 Vgl. Stephan Porombka, Turn on - tune in - drop out. Auf dem Weg zur säkular-sakralen Ästhetik der Netzkultur. In: Ästhetik - Religion - Säkularisierung II. Die Klassische Moderne, hg. von Silvio Vietta u. Stephan Porombka, München 2009, S. 265-279, hier S. 267. 
Martins „verruchter Lieblingsdichter“ (V 244), sich mit den Nationalsozialisten gemein gemacht hat. Das Gedicht endet mit einem Appell: „,[G]ib nun dem Boten die Krone, / Traum und Götter zurück““ (V 245). Im Anschluss tritt „[s]tatt des Boten, der Schmuck und Waffen des Abdankenden hätte an sich nehmen können“, die Krankenschwester Rosa ein und bringt Martin drei Schlaftabletten „wie eine Delikatesse“ (V 245). Beschrieben wird sie als „ein überanstrengter, aber noch in der Erschöpftheit hilfsbereiter und adretter Engel“ (V 244/245). Auch die Schlaftablette verführt in den Tod und wird später von Tilly zum Suizid verwendet.

In Tilly und ihrer Schwester Marion verkörpert sich der Konflikt zwischen Engagement und Gegenwartsflucht, der den gesamten Roman durchzieht. In den spiegelbildlich aufgebauten Passagen, in denen Tilly und Marion beide ungewollt schwanger sind und den Tod herbeisehnen, erinnern sie sich der früheren Sonntagsbesuche auf dem erlesenen Anwesen ihrer Großtante mit dem „reizend[en] und etwas verwunschen[en] Garten“ (V 294) als einer Art Garten Eden. Hier wird der Tod nicht nur mit dem Wunsch nach der Rückkehr in die Kindheit verknüpft, sondern er ist bereits in dieser verankert: Während Tilly, die die Veronaltabletten nimmt und stirbt, „ganz versessen darauf [war], den Gang aus der Sphäre des Lichts in die Grabkammer der fleckigen Billardkugeln und süßen Kuchen zu tun“ (V 296), kann Marion sich weder des Aussehens noch des Geruchs dieser Kammer erinnern - ,,[v]ersunkener Raum - ich finde den Zugang nicht ...““ (V 455). Sie wendet sich von dem tödlichen Kindheitsparadies ab und der Zukunft mit ihrem eigenen Kind und der Fortsetzung des politischen Kampfs zu.

Das Assoziationsfeld Tod - Engel - Kindheit - Paradies setzt sich fort in Marions Sohn, der als „petit camérade des anges“ (V 529) bezeichnet wird. Als der Engel der Heimatlosen erscheint, war „,s]ie [...] es - die junge Mutter -, die schrie; das Kind lächelte schon. Die Nähe des Engels war ihm angenehm; der kleine Marcel war erst vier Wochen alt, und dem Paradiese noch nicht fremd geworden“ (V 529). Der Engel als Figur liminaler Sphären besetzt den Ort des Übergangs; sowohl den Eintritt von der paradiesischen in die historische Zeit als auch den Austritt aus dieser als Schwelle von Leben und Tod.

Auch die verführerische Wirkung des Todes wird durch den Engel beziehungsweise die mit ihm assoziierte Schwerelosigkeit illustriert: Tilly sieht im Tod für die Wirtin „,so schön und friedlich aus, wie ein Engelchen““ (V 298), und die Zurückgebliebenen beklagen sich gegenüber der nun gewichtslosen Tilly: ,,[W]ir aber sind dick und schwer und voll Flüssigkeit, gar nicht vornehm.“ (V 301) Die Schwestern verdeutlichen so den schmalen Grat des engelsgleichen Lebens. Während Tilly ihn ganz überschreitet und stirbt, hält Marion, 
die immer dünner, aber nicht vollkommen körperlos wird, die prekäre Balance als prophetisch inspirierte, künstlerisch tätige Mittlerfigur.

Auch der Tod Martins, der geschwächt von seinem exzessiven Drogenkonsum an einer Lungenentzündung stirbt, erscheint in der Figurenwahrnehmung über den Engel verklärt: „,Er [Martin, L.Z.] hat dem Dunklen Engel Stirn und Lippen zum Kuß geboten. Der Dunkle Engel zog ihn innig an sich““ (V 310), behauptet Kikjou, der David selbst „,[w]ie ein Todesengel““ (V 310) erscheint. Tatsächlich erklärt der später auftretende Engel der Heimatlosen, er sei bei Martin gewesen, „, als er den Tod empfing wie eine Krone““ (V 518). Als erotische Schnittstelle von Tod und poetischer Initiation - Kikjou will dank des Engelskusses eine Chronik des Exils verfassen - steht der Kuss exemplarisch für die Ambivalenz der Engelsfigur. Diese kommt in der Erstarrung des Exilzustands zum Ausdruck und findet eine direkte Personifizierung in dem dämonischen NS-Spitzel Walter Konradi, mit dem der Topos der satanischen Engelstäuschung aufgegriffen wird. ${ }^{84}$ Zunächst erscheint er Friederike Markus als strahlender Engel Gabriel:

Friederike, die ihren Blick sehnsüchtig ausschickte, erkannte Gabriel; in höchst anmutiger Pose stand er gegen die Theke gelehnt. Er trug einen grauen Sportanzug mit weiten Pumphosen; von den Schultern wuchsen ihm silbrig-blaue Flügel, starr und leuchtend, wie angefertigt aus einem biegsamen, starren und spröden Metall. Unter einer schicken englischen Schirmmütze, die er tief in die Stirn gezogen trug, glänzten die Augen des huldreichen Engels derartig stark, daß Frau Viola sich zugleich entsetzt und beseligt fühlte.

Als sie schließlich die Täuschung von Konradi erkennt, der sie für seine politische Agenda benutzt hat, erscheint sie selbst bereits durch das Böse infiziert:

„Herr Erzengel Gabriel - sehr erfreut, Ihre Bekanntschaft zu machen! Jetzt erkenne ich Sie erst, mein Herr Erzengel: Sie sind ja der Teufel. Mes respects, Monsieur le Diable! Sehr geschmeichelt, Exzellenz Gottseibeiuns!“ - Dazu Verneigungen und stolze Schritte. ,Sie ist endgültig wahnsinnig geworden.' David beobachtete an die Wand gepreßt, das makabre Schauspiel. ,Was soll ich tun? [...] Wie sie selber satanisch wird, da sie sich vor dem Satan verneigt! Ich habe Angst. Das Böse ist stark - stärker als wir es ahnten; furchtbar stark in unserer erschütterten Zeit ... Wie komme ich von hier weg? Wenn sie nur aufhören wollte, zu grinsen! ... Oh - sie hat den Teufel im Leib!‘

(V 345-346)

84 Zum Topos der satanischen Engelstäuschung vgl. „[...] denn er selbst, der Satan, verstellt sich als Engel des Lichts“ (2. Kor 11,14). Auch die Erstarrung des Exils wird durch den Engel illustriert. In populärkultureller Verflachung seiner furchterregenden Komponenten und jeglicher dynamischer Potenz beraubt, ziert er sinnbildlich als Nippes das Interieur der im Exil stagnierenden Familie Rubinstein (vgl. V 48-49). 
Neben den verführerischen Irrwegen zu tödlichen Paradiesattrappen, die der syntaktischen Struktur der regressiven beziehungsweise inversen Apokalypse folgen, ${ }^{85}$ ist der Engel aber auch der zentrale Exponent des universalen Kampfs gegen das Böse, der explizit in einen heilsgeschichtlichen Zusammenhang gestellt wird. Einerseits machen Engel im Vulkan das Exil anschaulich - ohne angestammten Ort können sie in ihrer Unverortetheit im transitorischen Zwischenraum der Exilierten erscheinen. Andererseits illustrieren sie in dieser Ortlosigkeit die Utopie als Nicht-Ort, als Verweis auf eine andere Welt und einen anderen Menschen. ${ }^{86}$ Die Engel vollziehen so im Vulkan jene Entwicklung von einem exilfixierten Standpunkt hin zu einem transnationalen Zukunftsprojekt, die Klaus Mann selbst während seines Exils durchläuft.

\subsubsection{Angelisierung der Exilierten}

Die Politisierung des bloßen Lebens und der vernichtungsideologische Ausschluss aus dem Bereich des Menschlichen bedeuteten zunächst eine animalisierende Abwertung der Staatenlosen, deren Stigma im Vulkan mit dem anderen kontrastiven Term zur anthropologischen Bestimmung in eine Aufwertung verwandelt wird: dem Engel. So verkehrt sich die Situation einer umfassenden Mangelerfahrung der Exilantinnen und Exilanten - Verlust der Staatsbürgerschaft, Knappheit von Nahrung und Geld sowie fehlende Einheit, politische Durchschlagskraft und Akzeptanz - in der Art ihrer Darstellung in ästhetisch-überirdische Fülle. Dieser Umschlag funktioniert strukturell nach dem Prinzip des engelsgleichen Lebens.

Dem bios angelikos liegt der Gedanke zugrunde, man könne durch asketische Praktiken wie Fasten, Wachen und sexuelle Abstinenz seine irdischen Bedürfnisse überwinden und so zum Engel werden. ${ }^{87} \mathrm{Da}$ die Seligkeit der Engel eine Verheißung für das Leben nach dem Tod ist, nehmen diejenigen, die schon in ihrem irdischen Leben engelsgleich sind, den Zustand der Auferstehung vorweg. Die Präsenz einer überirdischen Zukunft in der irdischen Gegenwart ist eine an der Figur des Engels ausgerichtete Vorstellung. So knüpft sich

85 Vgl. Nagel, Ordnung im Chaos, S. 59-61.

86 Vgl. Cathrin Pichler, :Engel :Engel. In: Engel, :Engel. Legenden der Gegenwart, hg. von Cathrin Pichler, Wien 1997, S. 69-81, hier S. 74. Christina Thurner betont die diesbezügliche Affinität zwischen Exil und Utopie: „Die ,Utopie“ meint also wie ,Exil‘ eine Ortlosigkeit, indem sie gleichzeitig auf einen anderen, (noch) nicht existenten Ort verweist, während ,Exil` wiederum immer von der nicht mehr existierenden ,Heimat" aus zu denken ist“ (Thurner, Der andere Ort des Erzählens, S. 4).

87 Vgl. Kapitel 2.3 dieser Studie. 
die Vorbildfunktion von Engel-, Christus- und Prophetenfiguren wesentlich an ihre Tätigkeit als Mittler, ${ }^{88}$ die den Umschlag von irdischer Entbehrung in eine geistige, die Raum-Zeit-Koordinaten überschreitende Fülle verkörpern. Auf dieser Gedankenfigur basiert im Vulkan zum einen die ästhetische Strategie der Nobilitierung der Heimatlosen über ihre angelisierte Darstellung. Zum anderen bildet dieser Umschlag von Mangel in Fülle, der auch der Syntax der Apokalypse zugrunde liegt, ${ }^{89}$ das Prinzip des göttlichen Heilsplans, den der Engel der Heimatlosen Kikjou am Schluss des Romans offenbart.

Der Gedanke des engelsgleichen Lebens richtet sich an dem Ideal der körperlosen angelischen Reinheit aus. $\mathrm{Zu}$ ihr gelangt man über Praktiken, die von allen körperlichen Einverleibungen und Ausscheidungen befreien sollen. Dem Gedanken der Reinheit kam auch im Nationalsozialismus eine eminente Bedeutung zu, dort allerdings als biologistisch-prädeterminiertes, letztlich aber religiös bestimmtes Konstrukt einer „Reinheit des Blutes“90. Daraus wurde eine „Rasseneinheit“ abgeleitet als „kausale[r] Zusammenhang von Körperaussehen, inneren Eigenschaften und ,rassischen Werten““91. Auch hier fungiert der Körper als Ausgangspunkt eines wesentlich über religiöse Anleihen bewerkstelligten Transzendenzvollzugs:

Sowohl bei Chamberlain als auch im Nationalsozialismus ist der physisch-biologische Körper der Ort, in dem Transzendenz stattfindet, denn es ist im Körper, dass sich die „arische Rasse“ verwirklichen kann. Für Rosenberg ist die mystisch-religiöse Dimension von „Rasse“ und „Volk“ noch ausgeprägter. „Die echte nordische Seele ist auf ihrem Höhenfluge stets ,zu Gott zu' und stets ,von Gott her'. Ihre ,Ruhe in Gott‘ ist zugleich ,Ruhe in sich‘. Diese Art Umkehrung nach innen war für den NS-Ideologen der Schlüssel der ,nordischen Mystik‘ und ermöglichte das Transzendieren der bloßen physischen Existenz.“92

Das Konstrukt einer ,reinen Rasse` ist durch jegliche Form verunreinigender Vermischung bedroht. ${ }^{93}$ Folglich kam der Kontrolle von Sexualität und Reproduktion im Nationalsozialismus höchste Bedeutung zu. ${ }^{94}$ Gegensätze wie innen

88 Vgl. Frank, Angelikos Bios, S. 1.

89 Vgl. Nagel, Ordnung im Chaos, S. 55.

90 Paula Diehl, Körperbilder und Körperpraxen im Nationalsozialismus. In: Körper im Nationalsozialismus. Bilder und Praxen, hg. von Paula Diehl, München 2006, S. 9-30, hier S. 28. Vgl. dazu Raul Hilberg, Die Vernichtung der europäischen Juden, Bd. 1, Frankfurt am Main 2016, S. 77 sowie Raphael Gross, Gott und Religion in der Ethik des Nationalsozialismus. In: Nachleben der Religionen. Kulturwissenschaftliche Untersuchungen zur Dialektik der Säkularisierung, hg. von Martin Treml u. Daniel Weidner, München 2007, S. 177-187, hier S. 185.

91 Diehl, Körperbilder und Körperpraxen im Nationalsozialismus, S. 28.

92 Diehl, Körperbilder und Körperpraxen im Nationalsozialismus, S. 21.

93 Vgl. Diehl, Körperbilder und Körperpraxen im Nationalsozialismus, S. 28.

94 Vgl. Diehl, Körperbilder und Körperpraxen im Nationalsozialismus, S. 22 u. S. 29. 
und außen, oben und unten, männlich und weiblich, gesund und ungesund, rein und unrein oder heterosexuell und homosexuell stellen in ihrer trennscharfen Markierung das Fundament einer biologistischen Hierarchie dar. Nur auf dieser Basis ließ sich die realitätsferne und ohne ihr Anderes höchst unscharfe Projektion eines „arischen neuen Menschen“95 entwickeln und aufrechterhalten, für deren Konsolidierung auch die Figur des Engels herangezogen wurde. ${ }^{96}$ Dagegen beinhaltet die grenzüberschreitende Tendenz der Engel gerade die Überwindung binärer Terme, wodurch die sich auf diese stützende Ordnung ins Wanken gerät. ${ }^{97}$

In dieser Funktion wird der Engel im Vulkan für die Aufwertung des Hybriden und Abweichenden mobilisiert. Die Affirmation von heterogenen Identitäten spiegelt sich formal in der Auflösung von Zeit- und Raumeinheit des Erzählens sowie in der Breite und Transnationalität des Figurenspektrums. ${ }^{98}$ Im Gegensatz zu der nationalsozialistischen Norm des Gesunden sowie den restriktiven Geschlechterbildern sind fast alle zentralen Figuren im Vulkan überaus mager und androgyn. Sie erscheinen ätherisch und ungesund und opponieren damit nicht nur geistig, sondern auch körperlich der nationalsozialistischen Ideologie ebenso wie bürgerlichen Normen: „,Sehr verdächtige Gestalt‘, ist Herrn Korellas Eindruck von dem bleichen Knaben [Kikjou, L.Z.]. ,Wirkt kolossal ungesund. Ich bezweifle, ob seine Beziehungen zu meinem Martin sich überhaupt noch im Rahmen des Gesetzmäßigen gehalten haben ...““(V 321)

Viele der Figuren sind bereits zu Beginn des Romans sehr dünn oder magern in seinem Verlauf rapide ab. In diesem körperlichen Schwund drücken

95 Diehl, Körperbilder und Körperpraxen im Nationalsozialismus, S. 12. Vgl. auch die Erläuterung von Elke Frietsch: „In der gesellschaftlichen Realität war dieser [der ,arische‘, L.Z.] Körper nicht zu finden. [...] Letztlich blieb der ,arische Körper‘ eine Imagination und Utopie, die mit ästhetischen und weltanschaulichen Idealen in den Bereich der Kunst verwiesen wurde“ (Elke Frietsch, Helden und Engel. Unsterblichkeitsphantasmen in der Kunst des NS-Regimes während der Kriegsjahre. In: Körper im Nationalsozialismus. Bilder und Praxen, hg. von Paula Diehl, München 2006, S. 129-148, hier S. 129).

96 Vgl. zur Semantisierung des Engels im Nationalsozialismus Elke Frietsch: „Unsterblichkeitswünsche wurden nicht - wie etwa in der christlichen Religion - ins Jenseits, sondern ins Diesseits projiziert. Helden und Engel machten so das Unmögliche gewissermaßen möglich. Sie repräsentierten den ,arischen Körper‘ als vollkommen, ewig und wahr zu einer Zeit, in der gerade seine Gewaltsamkeit, Konstruiertheit und Unvollkommenheit durch die reale Zerstörung des Krieges immer stärker ins Blickfeld gerieten“ (Frietsch, Helden und Engel, S. 148).

97 Vgl. dazu Kapitel 2.1 dieser Studie.

98 Vgl. Tobias Lachmann, ,Exil‘ als literarisches Projekt. Nomadische Diskursformen in Klaus Manns ,Der Vulkan. Roman unter Emigranten‘. In: Nomadische Existenzen. Vagabondage und Boheme in Literatur und Kultur des 20. Jahrhunderts, hg. von Walter Fähnders, Essen 2007, S. 75-101, hier S. 86-87. 
sich die materiellen Entbehrungen des Exils aus. Allerdings bedeutet dieser Mangel keine Schwächung der Figuren; vielmehr verleiht er ihnen - der Logik der mönchischen Askese folgend - besondere Stärke und Noblesse. Diese ästhetische Überhöhung ist mit dem Engel verknüpft, der immer wieder zur Charakterisierung der Figuren herangezogen wird und sie der nationalsozialistischen Definitionsgewalt entzieht. Die Schönheit Meisjes, die „mit leuchtendem Haar und blanker Stirn [...] einem militanten Erzengel glich“ (V 281), wird wiederholt als engelsgleich charakterisiert, und über die Finger von David heißt es, sie seien „wie aus einer gewichtslosen, unirdischen Materie“ (V 100) gebildet. Er selbst ist „auffallend bleich und mager“ (V 13), seine Lippen „ungesund bläulich“ (V 17) gefärbt, und Marion imaginiert ihn als Propheten Jochanah (vgl. V 106). Mit den Engeln teilen Propheten, die ebenfalls als „göttliche Boten“99 wirken, das Verkünden einer höheren Weisheit und das damit verbundene Oszillieren zwischen medial-passiven und personal-aktiven Anteilen.

An deutlichsten zeigt sich dies an Marion von Kammer. Im Laufe des Romans wird sie zu einer gefeierten Rezitatorin im Kampf gegen den Faschismus und avanciert dabei wie die Engel zu einem Medium höheren Wissens. Auch sie ist sehr mager, mit „großen, jünglingshaft harten und sehnigen Hände[n]“ (V 21), und wird schließlich so dünn, dass sie angesichts ihres Spiegelbilds bemerkt: „So mager darf ein Mensch gar nicht sein.“ (V 256) Auch sie wird mit Prophetinnen - Kassandra und Pythia - verglichen, ${ }^{100}$ denen das drohende Unheil in apokalyptischen Visionen des Vulkans erscheint: „Als sie nachts neben ihm [Marcel, L.Z.] lag, sah sie wieder, vor den fassungslos geöffneten Augen, den feuerspeienden Berg, den Vulkan. Rauchmassen, lodernder Brand, und die Felsbrocken, die tödlich treffen. Wehe - was ist uns bestimmt?“ (V 281) Ihre purpurn schimmernden Haare ähneln einer cherubinischen „Löwenmähne“101, gleich einem Engel fungiert sie als Medium der Verkündung und erscheint

99 Wacker, Poetik des Prophetischen, S. 29.

100 Vgl. die rhetorischen Fragen des Erzählers: „Glich sie nicht einer Prophetin, mit dem bewegten Purpur-Schmuck ihres Haares? Solche Züge, solche Blicke hatte Kassandra“; „[a]uch ihr Gesicht war entstellt; Zuckungen um Mund und Augenbrauen ließen es fremd und beinah häßlich werden. War dies die Schmerzens-Raserei der Seherin?“ (V 507). Zur Konjunktur der Kassandra-Figur als Sinnbild in der Exilliteratur vgl. Theodore Ziolkowski, Mythologisierte Gegenwart. Deutsches Erleben seit 1933 in antikem Gewand, Paderborn; München 2008, S. 13-18.

101 Vgl. Kikjous Überlegungen anlässlich der ersten Engelsbegegnung: „Sein Haar ist fast eine Mähne -; ,eine Löwenmähne‘, stellt Kikjou fest -, sehr locker und üppig, wohl auch widerspenstig. [...] Kikjou konstatiert eine gewisse Ähnlichkeit mit Marions Haar - das freilich nur eine dezente Purpur-Nuance zeigt, während das Gelock des Engels schamlos flammt: blutrotes Feuer über der harten Stirn“ (V 350-351). 
dabei selbst als eine Art mysterium tremendum et fascinans: „Das überanstrengte Leuchten ihres Blickes war sowohl beängstigend als bezaubernd. Durch den gereckten Körper schienen Schauer zu laufen wie elektrische Schläge.“ (V 186) Armin Strohmeyer geht so weit zu sagen, „daß Marion selbst die Verkörperung eines Engels ist“"102. In jedem Fall evoziert sie jene Durchlässigkeit der Grenze zwischen Mensch und Engel, die dem bios angelikos zugrunde liegt.

Eine besondere Affinität zu Engeln hat auch die Figur, der zweimal ein Engel erscheint und die einen „Vogelname[n]“ (V 30) ${ }^{103}$ trägt: Kikjou. Dieser „problematisch[e] klein[e] Vagabun[d]“ und ,grüblerisch[e] Aventurier“ (V 317) ist „anstößig hübsch für einen jungen Mann“ (V 28), von schillernd-ambiguem Charakter und mit „vielfarbig schimmernden Augen“ (V 57). Kikjou spricht viel über Gott und trägt ein Kruzifix, seine Frömmigkeit hat aber eine Nähe zur Heuchelei und Martin wirft ihm vor, dass sie „,nur eine besonders unappetitliche Form [s]einer maßlosen Geilheit““ (V 220) sei. Wie die Entstehung der Engel ist Kikjous Herkunft undurchsichtig-hybrid, ${ }^{104}$ seine Verwandten leben in Rio de Janeiro, in Lausanne und Belgien. Er trägt die Züge des exotischen Fremden, der sich einer letztgültigen Einordnung entzieht und weniger menschlich als tierisch-engelhaft erscheint. Von dem Erzähler als „hündisch-sündiges Gewächs“ (V 348), von Gott als „schmiegsamer Gefährte Meiner Cherubim“ (V 539) apostrophiert, vereinigt er beide komplementären Abgrenzungsfiguren des Tiers (als reine Sinnlichkeit) und des Engels (als reine Geistigkeit), wobei sich, wie gezeigt, in der hybriden Figur des Engels die beiden Bereiche tendenziell vermischen. ${ }^{105}$ „[G]änzlich ohne Bindung und Vaterland“ ist Kikjou - anders als die „deutschen Flüchtlingen“ (V 540) - losgelöst vom Dispositiv des Nationalen und kann im Lauf des Romans zum designierten Menschheitsvertreter werden.

Die erste Engelserscheinung des Romans wird vorbereitet durch das Tableau der monastischen Existenz, in die Kikjou, nach Martins Tod von Selbstvorwürfen gepeinigt, sich zurückzieht. Die kärgliche Zelle als traditioneller Ort der geistlichen Imagination, ${ }^{106}$ das Fasten und Wachen, das Kauern auf dem Boden, die Einsam-

102 Strohmeyr, Traum und Trauma, S. 440. Dafür gibt es durchaus Hinweise im Text, etwa folgende Beschreibung von Davids Reaktion auf Marion: „Ihre Stimme, leuchtend zugleich und dunkel, hatte die Macht, sofort die gespannte Aufmerksamkeit aller im Raum wie durch einen Zaubertrick zu gewinnen. David, schreckhaft von Natur, warf, in jäher Drehung zuckend, den Oberkörper herum. Statt zu antworten, bedeckte er die Augen mit der Hand, als hätte zu starkes Licht ihn geblendet“ (V 107).

$103 \mathrm{Zu}$ den Parallelen von Engeln und Vögeln vgl. Macho, Himmlisches Geflügel.

104 Zur hybriden Herkunft der Engel vgl. Kapitel 2.2 dieser Studie.

105 Vgl. Kapitel 2.3 dieser Studie.

106 Vgl. Keppler, Gebet als poetogene Struktur, S. 351. 
keit und die Bußfertigkeit sind asketische Attribute beziehungsweise Exerzitien, die auf eine Annäherung an das engelsgleiche Leben abzielen. Kikjou wird dabei vom Erzähler instruiert: „Denke an alles, was du falsch gemacht hast - es ist reichlich viel! Nimm dir Zeit! Übereile nichts! Sei umständlich! Sei exakt! Rühre dich nicht, wenngleich dir die Knie schon wehtun!“ (V 348) Auch zur Nahrungsenthaltung wird er explizit angehalten: „Nicht essen und trinken jetzt! Es ist die Stunde der Konfession.“ (V 349) Ein biblisches Vorbild für die Engelserscheinung, der Trauern und Fasten vorausgeht, findet sich im Buch Daniel, das ebenfalls von einem Exil handelt, dem babylonischen Exil. Die letzte dort geschilderte Engelsoffenbarung beginnt folgendermaßen: „Zu der Zeit trauerte ich, Daniel, drei Wochen lang. Ich aß keine leckere Speise; Fleisch und Wein kamen nicht in meinen Mund; und ich salbte mich auch nicht, bis die drei Wochen um waren." (Dan 10,2-3)

Kikjou verbringt die Nacht wachend, betend und gestehend auf dem kalten Steinfußboden. In diesem Zustand der Selbstkasteiung erscheint ihm schließlich ein Engel. Dessen unruhiges und ein metallisches Klirren erzeugendes Flügelschlagen „,ist wie ein nervöser Tick; dabei aber sehr großartig“ (V 350). Er riecht nach Mandelblüten und feinem Benzin, ${ }^{107}$ trägt einen silbernen Overall und weckt Assoziationen nicht nur mit einem nervösen Sportler, sondern auch mit dem technischen Objektbereich: „Seine glanzumflossene Figur läßt, auf geheimnisvolle Weise, an ein starkes, elegantes Fahrzeug denken - an ein schnittiges Automobil oder ein flottes Motorboot“ (V 350). Auch er ist sehr schlank und sein Gesicht von „überanstrengter Magerkeit, wie man sie bei Sportsleuten findet“ (V 350). Als Kikjou sich zunächst weigert, mit ihm in den Schneesturm zu fliegen, offenbart sich die furchtbare Dimension des Engels:

Und ehe der zurechtgewiesne Knabe sich von seinem Schrecken erholen kann, hat der Engel sich sehr gräßlich verwandelt. Er flattert, er hebt sich, saust und kracht; er wird zum Bienenschwarm, wird zur eisigen Wolke, zur Flamme; er löst sich auf, sammelt sich wieder; scheint ein Raubvogel, der über Kikjou kreist; ein Flugzeug, surrend, mit starren Flügeln; ein Monstrum ohnegleichen ist der schlanke Jüngling geworden; auf den Knaben stürzt er sich, wie der Habicht auf das zitternde Lamm - wie Zeus, in einen Vogel verwandelt, sich auf Ganymed stürzt, so umklammert das himmlische Ungetüm mit furchtbar bewegten, furchtbar harten Gliedern den Kikjou. Hinaus in den Schnee! Hinaus in die Nacht! -: keine Barmherzigkeit kennt der Engel. Er ist selbst Schneesturm geworden, rasendes Element; seine Umarmung ist teuflisch, ist himmlisch, ist viel zu stark; überwältigend sind die Geräusche, die er hören läßt; Motoren-Lärm, holde Sphärenmusik, Raubvogel-Geheul, Stöhnen der Liebenden, gellendes Hohngelächter, tiefe, klagende Menschenstimme -: alles in Einem, betäubende Melodie.

(V 351-352)

$107 \mathrm{Zu}$ den intertextuellen Bezügen dieser Attribute hinsichtlich der Engel in Stefan Georges „Der Teppich des Lebens“ und Jean Cocteaus „L'ange Heurtebise“ vgl. Strohmeyr, Traum und Trauma, S. 291-296. 
In dieser teuflisch-himmlischen Umklammerung zeigt sich der Engel als Wesen, das konträre Extreme in unerträglicher Intensität umfasst. Auch diese überwältigende Wirkung des Engels erinnert an das Buch Daniel: „Es blieb aber keine Kraft in mir; jede Farbe wich aus meinem Antlitz und ich hatte keine Kraft mehr. Und ich hörte seine [des Engels, L.Z.] Rede; und während ich sie hörte, sank ich ohnmächtig auf mein Angesicht zur Erde.“ (Dan 10,8-10) Der Engel erscheint mit der elementaren Wucht der Naturkatastrophe als Verkörperung des Monströsen, von dem Rudolf Otto sagt, es sei „eben das Mysteriöse in Kraßheit“108, aber auch als Entfesselung menschengemachter Technik, die ihr Vernichtungspotential offenbart. Auf seinem Flug nimmt der Engel Kikjou mit zu einem Schauplatz des Spanischen Bürgerkriegs, wo Marcel im Sterben liegt und von Hans Schütte, der mittlerweile Politkommissar der Internationalen Brigade geworden ist, betrauert wird. Im Anschluss fliegen sie zu Marion, die sich gerade für eine Aufführung vorbereitet. Der Engel teilt ihr und dann auch Madame Poiret mit, dass Marcel tot ist.

\subsubsection{Verwandlung des Leids}

Für Kikjous Lebensführung hat die Begegnung mit dem Engel einschneidende Folgen. Er, der sich selbst rückblickend als „,faul und ohne Pflichten““ (V 515) beschreibt, wird zum politisch engagierten Menschen und übernimmt Verantwortung. So konnte man ihn, wie der sozialdemokratische Aktivist Theo Hummler an Marion schreibt, ,,unlängst in einer besonders heiklen Mission ins Reich schicken“" (V 434). Damit hat er jenen Auftrag umgesetzt, der ihm nach dem Flug mit dem Engel von Jesus übermittelt wurde. Als der Engel Kikjou wieder in seiner „mönchischen Zelle“ (V 359) abgeworfen hatte, empfängt „,[u]nfaßbar milde und unfaßbar streng [...] der Blick des Heilands diesen Sterblichen“ (V 359). Jesus erscheint als Inbegriff des menschlichen Leidens, „das Haupt voll Blut und Wunden“ (V 358), und er verknüpft sein Leid mit dem der Verstorbenen, Marcel und Tilly:

„Ich habe gelitten wie diese“, sagte der Heiland dem jungen Sterblichen. „Ich kenne die Schmerzen, deren Zeuge du gewesen bist. Auch du sollst leiden. Gehe hin. Nimm es auf dich. Es ist bitter, ein Mensch zu sein. [...] Weißt du aber nicht, wie sich das Bittere verwandelt? Leidend und liebend verwandelt sich der Mensch. Mein Vater im Himmel verzeiht uns, wenn wir geliebt und gelitten haben. Gehe hin, Knabe! Nimm es auf dich! Sei ein Mensch!“

(V 359-360)

108 Otto, Das Heilige, S. 98. 
Jesus, in dem in der christlichen Religion Menschwerdung und Passionsgeschehen untrennbar verquickt sind, verleiht dem Exil-Programm des Vulkans, das Erleiden und Menschwerden in eins setzt, eine passionstheologische Note. Während die Verwandlung des Menschen auf der Handlungsebene als Teil der Erlösung in die Zukunft verlagert wird, vollzieht sie sich im Vulkan selbst bereits in der Erzählgegenwart und zwar durch die Art und Weise, wie das Leid des Exils dargestellt wird. So leuchtet im Stillstand der Handlung eine andere Dimension auf, die über den rastlosen Überlebens- und Kampfbemühungen der Exilantinnen und Exilanten steht. Dies geschieht zum einen in Form von markierten Pausen, die in deutlichem Kontrast $\mathrm{zu}$ der maximalen Beschleunigung des Erzähltempos stehen. ${ }^{109}$ Während die erzählte Zeit stagniert, stellt der Erzähler Reflexionen zum apokalyptischen Brodeln an, wendet sich direkt an die Figuren und unterläuft damit immer wieder den dokumentarischen Charakter:

„Hüte dich, Marion! Wage dich nicht gar zu sehr in die Nähe des Schlundes! Wenn das Feuer dein schönes Haar erfaßt, bist du verloren! Wenn einer der emporgeschleuderten Felsbrocken deine Stirne streift, bist du hin! Auch könnte es sein, daß du am Qualm elend ersticken mußt. Hütet euch, Marion und Marcel! Furchtbar ist der Vulkan. Das Feuer kennt kein Erbarmen. Ihr verbrennt, wenn ihr nicht sehr schlau und behutsam seid. Warum flieht ihr nicht? Oder wollt ihr verbrennen? Seid ihr versessen darauf, eure armen Leben zu opfern? - Aber ihr habt nur diese! Bewahrt euch! Wenn auch ihr im allgemeinen Brand ersticken solltet -: niemand würde sich darum kümmern, niemand dankte es euch, keine Träne fiele über euren Untergang. Ruhmlos - ruhmlos, Marion und Marcel, würdet ihr hingehen!“'110

(V 165-166)

109 Vgl. Lachmann, Politische Schreib(-)Szene Exil, S. 237-238.

110 Mit nur geringfügigen Abweichungen wiederholt sich exakt diese Vision der Gefahr, die eng mit Sexualität verknüpft ist, und zwar als Marcel gestorben ist, Marion bereits in New York lebt und den Fensterputzer Tullio zum Liebhaber hat. Vgl. die Szene mit Marcel: „,Wovor fürchtest du dich?‘ - Er [Marcel, L.Z.] beantwortete ihre Frage mit einer Stimme, die plötzlich rauh war und etwas keuchte. ,Gefahren - Gefahren überall ... Oh, wir sind schon verloren! ... Welche Schuld haben wir auf uns geladen, daß man uns zu solcher Strafe verdammt? ... Ach, Marion - Marion ...' Seine Worte vergingen an ihrem Hals. Vielleicht weinte er. ,Wir werden schon fertig - mit allem!' raunte sie zuversichtlich. Aber auch ihre Augen hatten den entsetzten Blick, als wäre ein Abgrund jäh vor ihnen aufgesprungen. Aus dem Abgrund stiegen Feuerbrände, auch Qualm kam in dicken Schwaden, und Felsbrocken wurden empor geschleudert. Es war der Krater des Vulkans. Hüte dich, Marion!“ (V 165). Und später in New York: „Gefahren Gefahren, überall ... Oh, wir sind schon verloren! ... Welche Schuld haben wir auf uns geladen, daß man uns zu solcher Strafe verdammt? ... Marion und Tullio hatten den entsetzten Blick, als wäre ein Abgrund jäh vor ihnen aufgesprungen. Aus dem Abgrund stiegen Feuerbrände, auch Qualm kam in dicken Schwaden, und Felsbrocken wurden emporgeschleudert. Es war der Krater eines Vulkans. Hüte dich, Marion! Wage dich nicht gar zu sehr in die Nähe des Schlundes! Wenn das Feuer dein schönes Haar erfaßt, bist du verloren! Wenn einer der emporgeschleuderten Felsbrocken deine Stirne streift, bist du hin! Auch könnte es sein, daß du am Qualm elend 
Zum anderen vollzieht sich dieser Bruch der historischen Perspektive in religiös aufgeladenen Beschreibungen, die Tod und Leid des Exils im sakralen Bild transfigurieren. So ist eine religiös durchwirkte Schönheit Ausdruck der Verwandlung des Menschen durch sein Leid und Ergebnis der Verwandlung von Leid in Kunst, wobei (Menschen-)Leben und Kunst untrennbar ineinander verflochten sind. Beispiele dafür sind der Todeskampf und letztliche Tod Martins:

Erschauernd fiel die Mutter über sein Lager. Ihr graute; denn Martin, ihr armer Sohn, ward geschüttelt von Fäusten, die unsichtbar sind. Auch schien es ihr, daß er strahlte. Von seinem Gesicht, das gleich erstarren würde - die Mutter wußte es: nun würden sein Gesicht gleich erstarren - kam Glanz. Um sein immer noch aufgerichtetes Haupt, so schien ihr, zuckte ein Glorienschein wie von Blitzen, ein elektrisches Diadem, eine tödliche Krone.

(V 309)

Seit einigen Tagen ist er nicht mehr rasiert worden; ein blonder Bart - der auf der Oberlippe nicht mehr wächst - rahmt seine sanfte, strahlend bleiche Miene. So sind junge Märtyrer auf Heiligenbildern dargestellt - denkt stolz die Mutter. Was muß er alles durchgemacht haben, daß er so schön werden konnte!

(V 307)

Die Stillstellung im überhöhten Bild stellt ein Störmoment in dem linearen Fließen einer den Einzelschicksalen gegenüber indifferenten Geschichte dar. Dieses Prinzip wird im Vulkan als Bestandteil des Lebens reflektiert, das selbst schon kulturell überformt ist:

Bei sehr großen Affekten, in der Wollust oder in der Verzweiflung, bleibt den Menschen nichts übrig, als das festgelegte, klassisch stilisierte Bild zu stellen. Gerade die ungeheuersten Gemütsbewegungen drücken sich in der höchst konventionellen Pose aus. Das Individuelle tritt zurück; was bleibt ist der menschliche Ur-Typ. Tilly von Kammer - am Frühstückstisch in diesem Züricher Hotelzimmer - stellte, sich die Brust schlagend und das Haupt mit den tragisch blicklosen Augen langsam hin und her wiegend, das klassische Bild: Junge Frau, die Trauerbotschaft empfangend.

Auf diese Weise werden die Figuren über eine pathosformelhafte Stillstellung im archetypischen beziehungsweise sakralen Bild aufgewertet. In diesem ist die Kontingenz des einzelnen Schicksals aufhoben. Auch der Schrecken des Exils selbst, der sich im unmittelbaren Erleben als beispiellos darstellt, wird in einen transhistorischen Raum der Kultur überführt und damit gemindert. Auf

ersticken mußt. Furchtbar ist der Vulkan, das Feuer kennt keine Gnade. Ihr verbrennt, wenn ihr nicht sehr schlau und behutsam sein. Warum flieht ihr nicht? Oder wollt ihr verbrennen? Seid ihr versessen darauf, eure armen Leben zu opfern? - Aber ihr habt nur diese! Hütet sie wohl! Bewahrt euch! Wenn auch ihr im allgemeinen Brand ersticken solltet -: niemand würde sich um euch kümmern, niemand dankte es euch, keine Träne fiele über euren Untergang. Ruhmlos ruhmlos würdet ihr untergehen!“ (V 423-424). 
der Handlungsebene realisiert Marion diese Aufhebung des gegenwärtigen Leids durch ihr Vortragsprogramm mit dem Motto „Zeitgemäße Klassik“. Hier trägt sie aus Werken von Schiller, Lessing, Goethe, Heine, Victor Hugo, Gottfried Keller, Nietzsche und Walt Whitman vor und macht damit jene Verwandlung des Exils für ihr Publikum erfahrbar:

In jedem Vers und jeder Prosazeile, die sie ausgewählt hatte, gab es die Beziehung zum
Heutigen. [...] Die verewigten Meister schienen an dieses Jahr und an diese Stunde - an
dieses Auditorium und seine besonderen Leiden schienen sie gedacht zu haben, als sie
gewisse Dinge schrieben, die Marion nun zum Vortrag brachte. Die im Saale unten begrif-
fen: Weder unsere Leiden noch unsere Erkenntnisse sind so unerhört und so neu, wie wir
in der ersten Aufregung oft meinen wollten. Andere vor uns haben schon gelitten und
schon nachgedacht, und sind von den gleichen Problemen berührt worden wie wir. Aus
ihren Erkenntnissen und Schmerzen aber ist Schönheit geworden.

Durch die Parallelisierung der Leiden und Erkenntnisse der Exilantinnen und Exilanten mit den Leiden und Erkenntnissen der Dichter und Denker entsteht eine interexilische Schicksalsgemeinschaft, die die historische Linearität transzendiert: „Wie verklärte Brüder schauen sie [die Toten, L.Z.] uns ernst und freundlich an. Geisterhafte Zusammenhänge stellen sich her; aus den großen Toten sind neue Freunde geworden.“ (V 187)

Indem das Leben im Exil als eine anthropologische Konstante gezeigt wird, diffundiert die Linearität historischer Entwicklung ins Mythisch-Urbildhafte, was nicht nur durch die Vergegenwärtigung vergangener Dichtungen, sondern auch durch die schattenhafte Existenz der Staatenlosen bedingt ist - nach Hannah Arendt ist es ,jene komplette Rechtlosigkeit [...], die ihn [den Rechtlosen, L.Z.] sicherer als alle unmittelbare Gewalt von der Welt der Lebenden scheidet“"111. Diese über die Gegenwart hinausreichende Genealogie spiegelt sich auch im Aufbau des Romans, dessen drei Teilen jeweils Zitate vorangestellt sind, die Ruhelosigkeit, Einsamkeit und die Vertreibung aus dem Paradies thematisieren: von Hölderlin („Doch uns ist gegeben / Auf keiner Stätte zu ruhen [...]“ (V 12)), Nietzsche (,Wer das verlor, / Was du verlorst, macht nirgends Halt“ (V 194)) und Heine („Das goldene Zeitalter, heißt es, liege nicht hinter uns, sondern vor uns; wir seien nicht aus dem Paradiese vertrieben, mit einem flammenden Schwerte, sondern müßten es erobern durch ein flammendes Herz, durch die Liebe; die Frucht der Erkenntnis gebe uns nicht den Tod, sondern das ewige Leben“ (V 384)).

111 Arendt, Elemente und Ursprünge totaler Herrschaft, S. 442. 


\subsubsection{Auf „Dienst-Flug“ mit dem Engel der Heimatlosen}

Die Verwandlung des Leids im Raum der Kultur wird zum Schluss des Romans überboten durch eine Zukunftsvision vom Reich Gottes, die der Engel der Heimatlosen Kikjou als angelus interpres - ein erneutes Zitat des Buchs Daniel (vgl. Dan 9,20-23) - übermittelt. Wie bei den Heimatlosen, deren irdische Entbehrungen durch die angelisierte Darstellung ästhetisch transfiguriert werden, ist der Umschlag von leidvollem Mangel in Fülle auch konstitutiv für die Struktur der Apokalypse als Matrix des göttlichen Heilsplans. In diesen wird Kikjou eingeweiht, nachdem er die Lehre aus der ersten Engelserscheinung befolgt hat. So bescheinigt ihm der Erzähler: „Wo du auch gewesen sein magst - du bist dem Leben nicht ausgewichen; du hast dem Befehl gehorcht, den das sinkende Haupt, das Dornengeschmückte, mit trocken-rissigen Lippen dir zurief.“ (V 513) Der erste Engel erscheint Kikjou, als er betet und seine Sünden bekennt, und auch vor der zweiten Engelserscheinung hält Kikjou Zwiesprache mit Gott. Er denkt an das „Nahe, Irdische“ (V 516), an Passschwierigkeiten und finanzielle Nöte, aber auch an die Engel. Wieder ist die Voraussetzung für die Engelserscheinung eine asketische Situation: „Ist sie uns nicht vertraut, diese mönchische Zelle? Das Kruzifix an der grauen Wand, das schmale Bett, und auf dem Tisch die unberührten Speisen -: zu solcher Kargheit zwingt sich Kikjou.“ (V 513)

Kikjou, dessen Gesicht nun „härter, magerer und strenger“ (V 513) ist, wird erneut von einem Engel aufgesucht: „,[M]eines Amtes ist es, solche zu begleiten, die sich ohnedies schon rastlos unterwegs befinden. - Ich bin der Engel der Heimatlosen.““ (V 517) Entsprechend ist er ebenfalls in rastloser Bewegung an den transitorischen Orten der Exilierten $\mathrm{zu}$ finden:

„In engen Hotelzimmern, Schiffs-Kabinen Dritter Klasse, in den Warteräumen der Konsulate, den Vorzimmern der Comités, in billigen möblierten Stuben, in Hospitälern, in den Friedhöfen vieler Städte, in Eisenbahn-Coupés ohne Zahl, auf Schlachtfeldern, auf Bahnsteigen, in vegetarischen Restaurants, in Redaktions-Stuben, billigen Caféhäusern, in obskuren Klubs, in Lagern, wo sie leben müssen - zusammengepfercht wie das Vieh -: überall mein Blick, mein Lächeln, mein stummer Trost ...“

(V 518)

Wie seine Schützlinge sieht der Engel zunächst schäbig aus, mit einem zerrissenen Mantel und zerzausten Flügeln. Wie der Ewige Jude steht auch der Engel der Heimatlosen, „zu schrecklichen Märschen verflucht“ (V 519), ${ }^{112}$ repräsentativ für die Unrast der Heimatlosen. Auf Kikjous Frage, wieso er ihnen nicht ge-

112 Diese mythische Exilfigur wird im Vulkan auch im Zusammenhang mit dem Fluch der Sprache genannt, vgl. folgenden Kommentar: „Marcel scheint verdammt zum Sprechen, wie der Ewige Jude zum Wandern“ (V 256). 
holfen habe, reagiert der Engel zunächst ausweichend: „,Ich konnte nicht. Ich durfte nicht. Und ich wollte nicht. Die Pläne meines Gebieters sind dunkel. Dunkel - dunkel - dunkel ...““ (V 519) Als er von all dem Elend erzählt, das er gesehen hat, und seine Augen berührt, werden sie blind. Als Kikjou weiter insistierend nach dem Sinn des Leids fragt, verwandelt sich der Engel angesichts des allgegenwärtigen Elends in eine dämonische Figur; es kommt der höhnische Bescheid, dass eine Antwort Kikjou vernichten würde, begleitet von einem Lachen „wie aus Höllenschlünden“ (V 520). Dann aber erhält der Engel wieder himmlische Sterne als Augen, er bittet um Entschuldigung für seinen Anfall, der ihn aufgrund des allzu nahen Kontakts zu negativen Dingen überkommen habe.

Im Anschluss an den Kuss, der in Kikjou den Plan entstehen lässt, eine Chronik des Exils zu verfassen, nimmt ihn der Engel in einer Silberwolke mit. Er ermöglicht Kikjou Einblicke in verschiedene Exilsituationen, zeigt ihm, wie er den Heimatlosen hilft, und erläutert ihm schließlich die göttlichen Pläne. Auf diesem „Dienst-Flug“ (V 526) am 14. September 1938 werden verschiedene Heimatlose aufgesucht: zuerst Marion, Benjamin und ihr Kind in den USA, dann ein kleines Restaurant in Paris, wo der Engel David Deutsch beisteht, als er antisemitisch angegriffen wird. Als nächstes fliegt der Engel mit Kikjou in den Spanischen Bürgerkrieg nach Tortosa, wo Hans Schütte als Politkommissar tätig ist und der Engel der Heimatlosen den Refrain der Internationalen summt. Schließlich rettet er einen deutschen Deserteur vor dem Sturz in den Abgrund.

Dass über den Engel der Heimatlosen die für das nationalstaatliche Denken und damit auch die Exilsituation konstitutive Dichotomie von innen und außen transzendiert wird, ${ }^{113}$ zeigt sich an Kikjou, dem „Wahl-Emigrant[en]“ (V 514) als national unbestimmter Figur der radikalsten Entwurzelung. Er ist er „so gänzlich ohne Bindung und Vaterland - wie der Engel, der ihn geleitete“ (V 540). Und auch um Dieter, den deutschen Deserteur, kümmert der Engel sich, denn ,,[d]as Stigma der Heimatlosen - nicht im Exil, in der fremd-gewordenen Heimat hat er sichs erworben““ (V 540-541). Indem die Begriffe Heimat und Fremde hier aus ihrer geopolitischen Verankerung gelöst (,,heimatlos in der Heimat““(V 539)), also deterritorialisiert und damit auch in ihrer nationalstaatlichen Determinierung hinterfragt werden, sind sie einer politischen Rekonfiguration zugänglich. So finden sich im Vulkan bereits Ansätze für die dezidiert kosmopolitische Ausrichtung von Klaus Manns politisch-kulturellem Programm, das auf einen „neuen Humanismus“ und eine „Weltdemokratie“114 abzielt. Die Sphäre eines supranationalen Got-

113 Vgl. Lachmann, Politische Schreib(-)Szene Exil, S. 234.

114 Mann, Decision, S. 239. 
tesplans bildet den Fluchtpunkt, von dem aus die Überschreitung des nationalen Denkens gedacht wird. So kulminiert das metaphorisch geweitete und zugleich dialektisierte Verständnis von Heimat und Heimatlosigkeit in der Erläuterung des Engels bezüglich der „Väterliche[n] Konzeption eurer Vollendung, de[s] Göttliche[n] Wille[ns] zur Utopie“ (V 545). Der Engel erklärt, Gott verhänge „Unannehmlichkeiten“ (V 545) über die Menschen, damit sie endlich aufwachten: „Er versucht alle Mittel, zwecks Beschleunigung des Prozesses -: die sanften, wie die weniger glimpflichen. Krieg und Pestilenz, jede Art von Ruin, jede Form des Schmerzes, der Erniedrigung -: lauter erzieherische Tricks, im Sinn und Dienst der gnadenvollen Heils-Konstruktion.“ (V 545)

In der Reihe dieser Unannehmlichkeiten stellt das Exil einen konstitutiven Bestandteil des numinosen Heilsplans dar, wie der Engel ausführt: „An maßgebender Stelle neigt man zu der Ansicht, daß der Schmerz euch sowohl feinfühliger als auch tapferer macht. Der Umgetriebene, Unbehauste, überall-Fremde hat vergleichsweise gute Chancen, dem Allerhöchsten Plan gerecht zu werden.“ (V 545) ${ }^{115}$ Ganz dem geschichtsphilosophischen Dreischritt von Einheit - Exil - Einheit höherer Ebene entsprechend verkündet der Engel:

Mit einem Schwerte wurdet ihr vertrieben aus dem Paradies, mit einem Schwerte sollt ihr
es zurückerobern. Ihr müßt euch die Heimkehr erkämpfen, ihr Heimatlosen! Er bevorzugt
die flammenden Herzen - denn Sein Element ist das Feuer, Sein wehender Odem ist Glut.
Die Lauen sind es, die Er aus dem Munde speit. Wer gar zu lange traulich hockt, in der
Heimat, wird lau und lahm: es ist beinah unvermeidlich. Deshalb schickt der Liebe Vater
euch auf Wanderschaft. Den Staub vieler Landstraßen sollt ihr schlucken, das Pflaster
vieler Städte sollt ihr treten, viele Meere sollt ihr überqueren, und auch durch Wüsten
führt der lange Weg. Alle Erkenntnisse und Impressionen, die ihr sammelt, könnten, in
ihrer Summe, eine erste, leichte Ahnung von den Absichten und Plänen ergeben -: auf
dergleichen hofft der Herr.
(V 545-546)

Der Engel der Heimatlosen agiert hier als angelus interpres, der die göttlichen Pläne einem berufenen Menschen offenbart und deutet. Auf diese Weise wird der transkulturelle Heimatlose, den Kikjou exemplarisch verkörpert, zweifach ausgezeichnet: zum einen durch die privilegierte Position als Empfänger einer angelischen Botschaft, zum anderen durch die explizite Qualifizierung des Unbehausten, der „vergleichsweise gute Chancen“ habe dem „Allerhöchten Plan

115 Ein ähnlicher Gedanke findet sich auch in Feuchtwangers Roman Exil: „Viele engte das Exil ein, aber den Besseren gab es mehr Weite, Elastizität, es gab ihnen Blick für das Große, Wesentliche und lehrte sie, nicht am Unwesentlichen zu haften. [...] An diese Emigranten klammerten sich viele Hoffnungen innerhalb und außerhalb des Dritten Reichs. Diese Vertriebenen, glaubte man, seien berufen und auserwählt, die Barbaren zu vertreiben, die sich ihrer Heimat bemächtigt“ (Feuchtwanger, Exil, S. 137). 
gerecht zu werden“, da er durch den Schmerz „sowohl feinfühliger als auch tapferer“ (V 545) sei. Diese Überhöhung der Heimatlosigkeit, die im göttlichen Koordinatensystem kein Manko, sondern einen Vorzug darstellt, erinnert an Edward Saids Aufwertung der Exilierten durch ihr „kontrapunktisches Bewusstsein“, das aus der „plurality of vision“"116 entstehe.

Im Vulkan wird das Exil in seiner theologischen Einfassung ganz explizit zur transhistorischen Metapher, indem der Engel es zur tragenden Säule eines „Väterliche[n], Königliche[n] Experiment[s]“ (V 546) erklärt. ${ }^{117}$ Umgekehrt werden die scheinbar nichtigen Alltagssorgen im Exil nicht allein ästhetisch durch die angelisierte Darstellung der Heimatlosen aufgewertet, sondern ausdrücklich zu einem tragenden Moment des göttlichen Willens erklärt. Die Exilantinnen und Exilanten sind keine Ausgestoßenen, sondern Auserwählte, die eine „,exquisite Chance““ (V 546) erhalten und die durch ihre nomadische Daseinsform Gott besonders nah kommen. Im Kampf gegen den Nationalsozialismus geht es nicht nur um die menschliche Sache, sondern ebenso um die göttliche: „Unsere Schritte führen auch Ihn zum Ziel. Unser Sieg ist immer auch der Seine, unsere Entwürdigung wird Seine Schmach“ (V 547), wie der Erzähler feststellt.

Gott ist im Vulkan nicht nur nicht tot, sondern er kommt gegen Ende in einem fulminanten Monolog selbst zu Wort. Dieser Monolog bricht nicht plötzlich in die Erzählung ein, sondern wird über mehrere Stationen vorbereitet. Aus der internen Fokalisierung, in der Kikjous Zustand nach dem Engelsflug gezeigt wird, entwickelt sich eine allgemeine Reflexion des Erzählers, der nun nicht mehr aus einer zwar mitfühlenden, aber distanzierten Übersicht über die Exil-

116 In „Reflections on Exile“ betont Said einerseits: „[I]ts [the exile’s, L.Z.] essential sadness can never be surmounted“ (Said, Reflections on Exile, S. 173) und warnt vor einer Bagatellisierung, die mit der metaphorischen Verwendung des Exilbegriffs drohe. Andererseits meint er: „Seeing ,the entire world as a foreign land' makes possible originality of vision. Most people are principally aware of one culture, one setting, one home; exiles are aware of at least two, and this plurality of vision gives rise to an awareness of simultaneaus dimensions, an awareness that - to borrow a phrase from music - is contrapuntal. [...] There is a unique pleasure in this sort of apprehension, especially if the exile is conscious of other contrapuntal juxtapositions that diminish orthodox judgment and elevate appreciative sympathy" (Said, Reflections on Exile, S. 186).

117 Die Funktionalisierung des Negativen als ein dialektisches Moment des göttlichen Heilsplans findet sich schon bei Augustinus, bei dem das Böse zu einer Art rhetorischem Schmuck der Weltordnung erklärt wird: „Gott würde ja keinen Menschen geschaffen haben und erst recht keinen Engel, dessen künftige Schlechtigkeit er vorausgesehen hätte, wüßte er nicht ebenso, wie er sich ihrer zum Nutzen des Guten bedienen und so das geordnete Weltganze wie ein herrliches Gedicht gewissermaßen mit allerlei Antithesen ausschmücken würde“ (Augustinus, Vom Gottesstaat, S. 29). 
schicksale spricht. Vielmehr ist er zu ihrer Stimme geworden, und da die Heimatlosen ja als exemplarische, von Gott ausgezeichnete Menschen verstanden werden, spricht der Erzähler nun konsequenterweise als die Stimme der Menschheit: „Es ist unsere Erde; wir tragen die Verantwortung - was hier immer geschieht.“ (V 548) Diese Menschheitsstimme des Erzählers geht unmerklich in die Stimme Gottes über:

Von uns verlangt Er [Gott, L.Z.] dann: Handelt! Protestiert! Schreitet ein! - Er ruft die Kreatur zur Aktion, damit das kolossale Stinken nur endlich aufhöre. An euch liegt alles: alles liegt bei euch - spricht die Höchste Instanz. Nichts wird euch abgenommen, kein Engel hilft euch - nur als Beobachter sind die Cherubim unterwegs. Ich empfange Berichte - die Mein umfassendes Wissen bestätigen, nicht bereichern können. Ich resümiere, kalkuliere, verifiziere; Ich hoffe, leide, schluchze, gräme mich, freue mich; Ich frohlocke, verstumme; Ich warte. Ich bin geduldig.

(V 548)

Mit diesem Übergang von Erzählerstimme in Gottesstimme rückt der Erzähler in die Nähe Gottes, sodass sich hier analog zur Angelisierung der Figuren eine Apotheose des Erzählers vollzieht. Der Eindruck einer quasigöttlichen Stimme wird verstärkt durch das umfassende Wissen des Erzählers über die Figuren (sein artikuliertes Nichtwissen ist meist ein rhetorisches) und seine olympische Übersicht über das Geschehen. Eine weitere Parallele besteht in der Angelisierung der Figuren, das der Erzähler durch sein Erzählern betreibt und das Gott dann explizit zum Menschheitsprogramm erhebt, wenn er den Engel der Heimatlosen zum Vorbild für die menschliche Entwicklung erklärt: „Der Engel der Heimatlosen hat ein Menschen-Gesicht - von der Art, wie es sein sollte und werden muß. Ich liebe Diesen, der unter Meinen Engeln der Geringste ist, weil Ich euch und eure Zukunft liebe.“ (V 549)

Für die vielfachen ästhetischen und rhetorischen Verwandlungen und Überschreitungen des Vulkans ist der Engel der Heimatlosen als der menschlichste unter den Engeln nicht nur als Zielpunkt der anthropologischen Teleologie zentral. Er etabliert auch die dafür notwendige Verbindung zwischen menschlicher und göttlicher Sphäre. Denn als Vermittlungsglied zwischen dem realhistorischen Leid der Heimatlosen und der transhistorischen göttlichen Sphäre übernimmt der Engel, der „Menschenworte“ (V 542) spricht, die für den menschlichen Wahrnehmungsapparat adäquate Übermittlung der göttlichen Pläne. Am Ende des Romans bestätigt Gott die Botschaft des Engels, indem er seine fordernde Liebe zu den Menschen offenbart und Chaos und Leid einen Sinn verleiht:

Ich liebe euer Blühen und euer Verwelken. Mich erschüttert eure Anmut und eure Häßlichkeit. Alle Gesten, mit denen ihr euer Leben verbringt, sind Mir Gegenstand des gerührten Entzückens. Das Herz des Vaters ist Flamme. Es brennt, es verzehrt sich in Flammen der Zärtlichkeit. Dies sollt ihr nicht wissen. Der Liebe Vater verbirgt, stolz und schamhaft, Sein ungeheures Gefühl. Er verhüllt den Blick; Er verschweigt das Wort. Mit liebender Geduld harrt Er jener Stunde entgegen, von der ihr nichts wissen sollt -: der Hochzeitlichen 
Stunde, der Stunde der Kommunion, dem Erlösungs-Fest, dem Feiertag des Großen Kusses, des Erlöschens ... Mit Schauern von Glück und Angst harrt der Vater, geduldet Sich der Große Liebende. - Ihr aber sollt im Schweiße eures Angesichts erledigen, was euch aufgetragen: Euer Erden-Pensum. Die Pläne und Absichten sind zu erfüllen - ob es auch Ströme von eurem Blut und euren Tränen koste. Seid wachsam und tapfer -: dies fordert Meine Liebe von euch! Seid energisch, seid realistisch, seid auch gut! Plagt euch! Kämpft! Habt Ehrgeiz und Leidenschaft, Trotz, Liebe und Mut! Seid rebellisch! Seid fromm! Bewahrt euch die Hoffnung! Steht auf eigenen Füßen!

(V 550)

Dieser Gottesmonolog ist aber für die Romanfiguren nicht mehr zu vernehmen. So spricht Gott zu Kikjou, der unter den Figuren der himmlischen Sphäre am nächsten gekommen ist: „Nein - natürlich kannst du Mich nicht verstehen. Deine Entrückung ist ja zu Ende, und übrigens hätte nicht einmal der Engel dir die Ohren öffnen können für Meine Stimme. Du bist irdisch, und du sollst es bleiben.“ (V 549) Auf der Grundlage der Prämisse, dass irdische und überirdische Sphäre in letzter Konsequenz getrennt sind, werden implizit auch die Leserinnen und Leser des Vulkans von jener Transzendierungsbewegung ergriffen, da sie, die die göttliche Stimme (über die Lektüre des Romans) vernehmen können, offensichtlich als nicht irdische entworfen werden.

Über das Herausstreichen der Fragwürdigkeit des angelischen Übersetzungsunterfangens bleibt der Gedanke der Unfassbarkeit Gottes romanintern gewahrt: „Göttliche Andeutungen, ein Nicken, Winken, Schluchzen, versuchen sie [die Engel, L.Z.] in Menschenworten auszudrücken -: die Formulierung bleibt ungenügend; das Resultat konfus.“ (V 546) Die Romanfiguren wissen also nicht, ob der von dem Engel der Heimatlosen übermittelte Heilsplan tatsächlich Gottes Absichten entspricht. Durch die Figur der vernehmbaren Unvernehmbarkeit wird an dem Gedanke einer kategorial anderen, nicht wahrnehmbaren Ordnungsmacht festgehalten, von der dennoch eine Mitteilung in die Welt der Menschen kommt. Um diese Paradoxie möglich zu machen, bedarf es neben der markierten Differenz von unwissenden Romanfiguren und eingeweihten Leserinnen und Leser eines Prinzips, das an beiden Sphären partizipiert. Der Engel der Heimatlosen als rastloser Verwandlungskünstler ist selbst von dem modernen Exil betroffen. Entsprechend „sonderbar“ nimmt er sich in Gottes „Hofstaat“ aus, wie dieser bemerkt, „mit dem bestaubten Melonen-Hut, dem zerschlissenen Kleid“ (V 548). Gleichzeitig aber ist er Teil einer Sphäre, die sich dem totalitären Herrschaftsanspruch des Nationalsozialismus konsequent entzieht. Als Repräsentant einer religiösen Ordnung transportiert er die Kraft religiösen und das heißt hier wesentlich sinnhaften Sprechens in einer strukturell von Kontingenz und Nihilismus bedrohten Zeit.

Die transzendente Sphäre bietet sich in dieser Konstellation auch deshalb als Sinnspenderin an, weil sie nicht in innerweltlichen Konfrontationen, in denen die Exilantinnen und Exilanten ohne Chancen sind, delegitimiert werden 
kann. ${ }^{118}$ Das Numinose, Ermöglichungsgrund und Zielpunkt der exilischen Transzendierungsästhetik, ist allerdings nicht nur dem Zugriff der hegemonialen Semantik entzogen; auch für die ausgeschlossenen Exilierten ist seine Verwendung nicht unproblematisch. Zwar sind zu Beginn des 20. Jahrhunderts spirituelle und religiöse Bewegungen in der deutschsprachigen Literatur weit verbreitet. ${ }^{119}$ In das Unterfangen einer Dokumentation und Analyse der antifaschistischen Emigration und ihrer handfesten Existenznöte ist ein göttlicher Heilsplan dennoch nicht bruchlos $\mathrm{zu}$ integrieren, ohne Gefahr $\mathrm{zu}$ laufen, das ganze Unternehmen zu diskreditieren. Klaus Mann selbst ist sich dessen bewusst, wenn er etwa die Fragwürdigkeit des Engels in Gides Roman Les FauxMonnayeurs reflektiert: „Nun ließe sich freilich einwenden, daß die Figur des Engels im Rahmen eines modernen Romans ja an sich schon ein bedenkliches Zugeständnis an den romantischen Geschmack bedeutete, ein Abgleiten von der kühlen Höhe psychologischer Analyse in die schwüle Tiefe mystischer Inspiration.“120

Der Vulkan ist durchaus selbst von einem Abgleiten ,in die schwüle Tiefe mystischer Inspiration“ bedroht, in die die Engel den modernen Roman hinabzuziehen drohen. Entsprechend wird eine göttliche Ordnung im Vulkan auch nicht vermittlungslos gesetzt - der Engel als Begegnungsgehilfe der zwei Sphären vermag nur deshalb zu überzeugen, weil sich in ihm die tiefen Ambivalenzen der Moderne spiegeln und er Elend und Armut der Exilierten selbst erleiden muss. Er stellt kein anachronistisches Relikt dar, sondern erfährt im Kontext der condition moderne eine Umkodierung, durch die er genuin moderne Eigenschaften wie Maschinenhaftigkeit, Technikaffinität, Rast- und Ortlosigkeit sowie regressive Sehnsüchte umfasst und zugleich wesentlich über die Beschränktheit der Zeitumstände hinausweist. Stilistisch wird diesem Umstand Rechnung getragen, indem alles Mystizistische durch die parodistische Überzeichnung des himmlischen Bürokratieapparats austariert wird. So erscheinen die Engel zwar einerseits als allgewaltig-elementare Mächte, andererseits müssen sie sich strikt an dienstliche Vorschriften halten, wie der Engel der Heimatlosen erklärt:

„Nun muß ich Bericht erstatten, und alle Details dieses Dienst-Tages treulich melden. Mein Herr wird unwirsch, wenn ich nur das Mindeste vergesse. Seine Neugier ist ebenso grenzenlos wie Sein Wissen - das Er sich durch unsere Reporte immer wieder bestätigen

118 Vgl. Koschorke, ,Säkularisierung، und ,Wiederkehr der Religion‘, S. 256.

119 Vgl. Martina Wagner-Egelhaaf, Entangled. Interdisziplinäre Modernen. Eine literaturwissenschaftliche Moderation. In: Moderne und Religion. Kontroversen um Modernität und Säkularisierung, hg. von Ulrich Willems, Detlef Pollack u. Helene Basu, Bielefeld 2013, S. 203-234, hier S. 207-208.

120 Klaus Mann, André Gide und die Krise des modernen Denkens, Reinbek 1995, S. 179. 
und gleichsam auffrischen läßt. Er ist sehr pedantisch, bei all Seiner Majestät ...“ - Nicht anders klatschen Beamte über den Vorgesetzten.

(V 542)

Die Überzeichnung, die dem himmlischen Hofstaat hier zugemutet wird, diskreditiert die religiöse Ordnung indes nicht, sondern erlaubt es vielmehr, deren Wirkmächtigkeit auch im politisch-sozialen Raum der Moderne zu behaupten. In den bürokratischen Abläufen kommt auf humoristische Weise die Anbindung an einen übergeordneten religiösen Ordnungsrahmen zum Ausdruck, der gegen das Chaos der irdischen Zustände installiert wird, ohne dass dabei die modernen Zeitumstände ausgeblendet werden. Das Medium dafür stellt der Engel dar, über den das christliche System modernespezifisch aktualisiert wird.

Dass der Entwurf einer göttlichen Heilsordnung keine artistische Spielerei ist, darauf deutet neben der Ernsthaftigkeit des Exilthemas eine erdachte Tagebuch-Aufzeichnung aus dem Wendepunkt hin, ${ }^{121}$ die sich mit den Ausführungen im Vulkan deckt, nach denen das Schicksal Gottes und das der Menschen untrennbar zusammenhängen:

Er braucht uns ... Diese Einsicht involviert Verantwortungen ungeheurer Art. Gott will, daß wir Ihm gefällig seien, hier und jetzt, auf unserem irdischen Plan. Andere Welten gehen uns nichts an. Ich glaube, daß es andere Welten gibt; aber sie haben keinen Bezug auf unsere hiesige jetzige Pflicht, unser jetziges, hiesiges Drama. [...] Er braucht uns. Wenn wir uns im Endlichen nicht erfüllen, bleibt auch Seine Unendlichkeit unerfüllt. Unsere Niederlage wäre auch die Seine; unsere Lüge beeinträchtigt Seine Wahrheit; unsere vergängliche Schande entstellt, versehrt Sein unvergängliches Bild. Je mehr ich an Gott denke, je inniger ich mich mit Ihm beschäftige, desto deutlicher wird mir die enorme Wichtigkeit, die metaphysische Relevanz unserer jetzig-hiesigen Probleme und Affären. ${ }^{122}$

Aus dieser Gedankenfigur heraus, dass der irdischen Misere unmittelbare Bedeutung für das Metaphysische erwächst, setzt Klaus Mann im Vulkan gegen die spirituell verarmten und entmenschlichten Umstände der Jahre 1933 bis 1939 mit einigem Kraftaufwand die Dramaturgie einer progressiven Apokalypse. Diese beinhaltet einen göttlichen Heilsplan, der im gegenwärtigen Krisenzustand zwar auf der Kippe steht. Seine Umsetzung wird aber, die mutige und tätige Mithilfe der Menschen vorausgesetzt, durch den Engel der Heimatlosen und den mönchischen Kikjou in Aussicht gestellt. Damit wird ein altes Bündnis

121 Das elfte Kapitel „Entscheidung“ trägt die Überschrift „Aus einem Tagebuch“, weist das Folgende also strenggenommen auch nicht als die Aufzeichnungen Klaus Manns aus. Ein Abgleich sowohl mit der unvollständigen Ausgabe der Tagebücher Klaus Manns von 1995 als auch mit den vollständigen Tagebüchern, die das Münchner Literaturarchiv Monacensias 2012 online bereitgestellt hat (vgl. http://www.monacensia-digital.de/content/titleinfo/13073), zeigt, dass es sich um andere Aufzeichnungen handelt.

122 Mann, Der Wendepunkt, S. 593-594. 
zwischen Mönch und Engel reaktiviert, die sich gegen die Feinde Gottes stellen. ${ }^{123}$ Wichtig ist hier, dass es sich nicht um eine religiös verbrämte Wiederkehr des neuzeitlichen Fortschrittsoptimismus handelt, sondern diese Entwicklung als eine außerweltlich sich vollziehende gedacht wird, der der Mensch tätig zuarbeiten kann (und soll). Dem Roman liegt die Struktur eines „apokalyptischen Aktionismus“124 zugrunde, der die gegenwärtige Misere nicht duldend hinnimmt, sondern in Rekurs auf eine transzendente Gesetzesstruktur die göttliche Erlösung in der Welt zu forcieren sucht. In Anbetracht der barbarischen Zeitumstände, die Abfassung, Struktur und Inhalt des Vulkans bestimmen, erhält das Ringen um Menschlichkeit eine Dringlichkeit, die Kunst und Engagement, vereinigt in der Galionsfigur des Engels der Heimatlosen, zu Bündnisgenossen macht. Als auserwählter Mensch tritt der Schriftsteller als prophetischer Chronist hervor, der in seiner Vermittlung transzendenter Inhalte selbst eine engelhafte Strukturstelle besetzt.

\subsubsection{Chronik des Exils: Der „Roman der Heimatlosen“}

Der Engel der Heimatlosen offenbart nicht nur einen göttlichen Heilsplan, der dem Leid des Exils eine höhere Bedeutung verleiht, er schreibt dem Romangeschehen auch eine (auto-)poetologische Wendung ein. ${ }^{125} \mathrm{Zu}$ Beginn ihrer Begegnung hatte der Engel Kikjou geküsst und ihm damit den Plan eingegeben, den „,,Roman der Heimatlosen““ (V 525) zu schreiben. Die Kuss- und Segensbotschaft wird nicht nur von dem Engel der Heimatlosen gesprochen: „Sehr viele Engel - die Heerscharen allesamt - schienen ihrem ramponierten Bruder Gewalt und Süßigkeit ihrer Kehlen zu leihen.“ (V 520) Angesichts dieser überwältigenden Präsenz weint Kikjou, weicht zurück und fleht den Engel an. Der Engel spricht sein traditionelles ,,Fürchte dich nicht!““ und drängt ihn in eine Ecke. In diesem Moment verlieren sich die körperlichen Konturen des Engels im Glanz, nur die Augen „blieben fest umrissen, bei all der strahlenden Auflösung“ (V 521). Dieser Auflösung entspricht, dass das zweite „,Fürchte dich nicht!““ von oben, und, so lässt sich mutmaßen, von den anderen Engeln oder von Gott kommt, da der Engel auf der Erde steht.

Gegen seinen Willen empfängt Kikjou einen eisigen Kuss und mit ihm die Eingebung, die Textfragmente von Martin und Marcel zu einer „,genaue[n] Chronik unserer Verwirrungen, Leiden, auch der Hoffnungen“ (V 522) zu mon-

123 Vgl. Frank, Angelikos Bios, S. 97.

124 Nagel, Ordnung im Chaos, S. 64.

$125 \mathrm{Zu}$ der autopoetologischen Dimension des Vulkans vgl. Thurner, Der andere Ort des Erzählens, S. 227 u. S. 229. 
tieren. Er soll sie im „Roman der Heimatlosen“ vollenden und so „,[d]as Verwirrte übersichtlich [...] machen; den Schmerz [...] lindern, indem man ihn analysiert““ (V 524). Der Titel des Romans stellt eine direkte Verbindung zum Engel der Heimatlosen her, der spätestens hier zur autopoetologischen Reflexionsfigur wird. Der Engel lässt sich mit seinen Attributen des Transitorischen und Unheimlichen als eine Figuration des exilischen Zustands begreifen. Dessen Gebrochenheit wird in der Angelophanie sowohl ausgestellt als auch momenthaft überwunden, indem die Vertreibung des Körpers als Grundlage von Kommunikation in der ätherischen Präsenz des Engels suspendiert ist. Als Vergegenwärtigung von Abwesendem stellt die narrativierte Exilerfahrung überdies, wie gezeigt, eine Strukturanalogie zur Tätigkeit der Engel dar, die den abwesenden Gott vertreten.

Heimatlosigkeit meint im Vulkan die konkrete historische Situation, begreift aber auch den metaphorischen Überhang der condition moderne ein. So heißt es in dem Vorwort zu Martins Roman, das Teil von Kikjous Roman werden soll:

Es ist eine große Unruhe in der Welt. Nicht nur die, welche ihr Vaterland haben verlassen müssen, irren wie Heimatlose umher. Mit einer Dringlichkeit und einer Angst, mit einer Verzweiflung und einer Hoffnung, wie seit Jahrhunderten nicht mehr, stellt der Mensch sich die Frage nach seiner Bestimmung, seinem Schicksal, seiner Zukunft auf diesem Stern. $\mathrm{Zu}$ einem Gott, dessen Antlitz sich uns verhüllt, steigt zu jeder Stunde eines jeden Tages hunderttausend Mal der Schrei: Herr, wohin führst du uns? Was hast du vor mit uns, Herr? Welches ist der Weg, den wir gehen sollen? Siehe: wir sind im Begriffe, uns sehr schlimm zu verirren!

(V 190)

Damit ist jene Grunddisposition der Heimatlosigkeit als diskontinuierlicher Seinszustand in der Moderne umschrieben, der von den Exilierten auf existentiell zugespitzte Weise repräsentiert wird - ihre Anrufung Gottes hat „,,den dringlichsten Ernst, die meiste Inständigkeit““ (V 190). Als einer von ihnen will Martin „,der Chronist [...] sein ihrer Abenteuer und Niederlagen““ (V 190). In der Wendung „,[m]ir ist aufgetragen““ (V 190) drückt sich ein prophetisches Sendungsbewusstsein aus. Der poeta vates degradiert sich zum Empfänger einer höheren Direktive, der er Folge zu leisten hat - Martin will kein genialisches Werk schaffen, sondern als Seismograph fungieren, der „,die tausend Formen und Gebärden, in denen diese Frage [nach dem göttlichen Plan, L.Z.] sich ausdrückt"“ (V 190), aufzeichnet und bewahrt. ${ }^{126}$

126 Christina Thurner verweist in diesem Zusammenhang auf die Nähe zum Verständnis des Chronisten bei Walter Benjamin, der sich der Erinnerung in einem Moment aufblitzender Gefahr bemächtigt (vgl. Thurner, Der andere Ort des Erzählens, S. 190-191). 
Gleichzeitig legitimiert und beglaubigt die höhere Inspiration über das biographisch verbürgte Leiden des Exils hinaus den Wahrheitsgehalt der Worte und sakralisiert den Sprecher. Neben die medial-registrative Komponente der heteronomen Rede tritt daher das Bild der Erwähltheit des Einzelnen, der für diese Aufgabe berufen und vor anderen ausgezeichnet ist. So spricht Martin von seinem „,Ehrgeiz, Chronist zu sein““ (V 190). Die intermediäre Stellung in der Trias Gott - Mittler - Mensch, die mediale Demut, aber auch das Selbstbewusstsein als „Wahrheitsorgan“127 beinhaltet, korrespondiert der Vermittlungslogik des Engels. Wie dieser stellt der Prophet, zu dem eine apokalyptische Nähe besteht (vgl. Offb 22,9), die Scharnierstelle zwischen einer numinosen Sphäre und dem realhistorischen Schicksal der Entwurzelten dar, deren Leid vor dem Vergessen geschützt werden soll.

Die Dimension des Bewahrens verweist auf die zweite Vermittlungsleistung, die zwischen den Zeiten und Generationen. Sie ist aus der Not der aktuellen Umstände geboren, in denen „,[u]nser Ruf““ (V 191), von dem Chronisten getragen, ungehört zu verhallen droht: ,,Für wen schreibe ich? - Immer haben Dichter sorgenvoll darüber nachgedacht. Und wenn sie es gar nicht wußten, dann haben sie wohl - hochmütig und resigniert, stolz und verzweifelt - behauptet: Für die Kommenden!““ (V 191) Der prophetischen Genealogie sich einschreibend sieht Martin die Überwindung der Verfinsterung voraus: „,Die Katastrophen aber sind kein Dauerzustand. Die Himmel, die wir heute so tief verschattet sehen, erhellen sich wieder.““ (V 191) Der Chronist hört schon die Schritte der Jüngeren; deren „,Stirnen sind noch blank von einer Unschuld, die wir längst verloren““ (V 191). Dank der Überlieferung dieser kampfgeprägten, schuldbehafteten Zeit aber kann die Angehörigen der kommenden Generationen eine Ahnung überkommen, „was von uns gesündigt und bereitet, durchkämpft und gelitten worden ist - und wir sind nicht vergessen“ (V 192).

Nachdem im Romanverlauf die schriftstellerischen Bemühungen Marcels und Martins an dem Märtyrerwunsch beziehungsweise einer Verweigerung von politischer Verantwortung gescheitert waren - Marcel opferte sich auf dem Schlachtfeld des Spanischen Bürgerkriegs, Martin ging an seiner Drogensucht zugrunde -, wird deutlich, dass nur die Vermittlung der sozialpolitischen mit der ästhetisch-religiösen Sphäre zukunftsträchtig ist. An die Stelle von Marcel und Martin tritt Kikjou, der von dem Engel der Heimatlosen einen mystagogischen Segenskuss erhält. Dem Vorwurf der Eitelkeit und des Ehrgeizes, den der Engel erhebt, begegnet Kikjou ebenfalls mit der für den Dichter-Propheten charakteristischen Demutsgeste, ${ }^{128}$

127 Wacker, Poetik des Prophetischen, S. 37.

128 Vgl. Wacker, Poetik des Prophetischen, S. 37. 
indem er auf seinen medialen Status im Dienst der Sache verweist: „,Meine Stimme soll die Stimme meiner Brüder sein - der lebenden wie der toten -: nach Diktat will ich sprechen.““(V 524)

Kikjous Roman soll dabei nicht nur eine Verbindung zwischen den Zeiten stiften, sondern hat auch eine Funktion im gegenwärtigen Kampf: „,Du sollst eine Schlacht gewinnen!““ (V 524), „,[d]as Wort ist, immer noch, eine gute Waffe!““ (V 525), ${ }^{129}$ wie der Engel Kikjou mitteilt. Als religiös Inspirierter agiert der Schriftsteller hier nicht nur als Seismograph der gegenwärtigen Entmenschlichung, deren Opfer er vor dem Vergessen bewahrt, sondern auch als Eingeweihter, der dank dem Engel von einer höheren Ordnung weiß und somit aus einer anderen, zuversichtlicheren Perspektive schreiben kann. Während Martin und Marcel im Drogen- beziehungsweise Heldentod verstummten, besteht Hoffnung für Kikjous Unternehmen. Zu jenen kam der Engel in ihrem Sterben, Kikjou hingegen wird im Leben von ihm aufgesucht, ausgezeichnet und auf herausragende Weise qualifiziert, dem Unsagbaren eine Sprache zu geben, es durch begriffliche Analyse und Ordnung fasslich zu machen: „Man muß geflogen sein mit den Engeln, man muß mit den Armen gehungert haben - wenn man Bücher über Menschen schreiben will.“ (V 527)

Dabei ist im Folgenden nicht unbestimmt von einem Buch die Rede. Vielmehr wird zum adäquaten Medium dieses Unterfangens ausdrücklich der Roman erhoben, dessen „Krise“ in den 1920er Jahren noch debattiert wurde. ${ }^{130}$ Da der Roman der Heimatlosen die vielen Romane der Einzelschicksale bündeln soll, ${ }^{131}$ ist ihm die „Redevielfalt“"132, die Michail Bachtin dem Roman attestiert, in besonderem Maße eigen. Durch die synchron wie diachron wirksame Dialogizität ist er

129 Neben der Aufforderung zum Kampf liegt darin auch das Versprechen, die Krise des Worts zu überwinden, an der Marcel verzweifelt war (zu einer ethisch motivierten Sprachkritik im Vulkan vgl. Thurner, Der andere Ort des Erzählens, S. 187-189; zum Sprachexil im Vulkan vgl. Susanne Utsch, Sprachwechsel im Exil. Die „linguistische Metamorphose“ von Klaus Mann, Köln; Weimar; Wien 2007, S. 285-310).

130 Vgl. Dietrich Scheunemann, Romankrise. Die Entstehungsgeschichte der modernen Romanpoetik in Deutschland, Heidelberg 1978.

131 So spricht der Engel der Heimatlosen zu Dieter: „Dein Roman ist noch nicht zu Ende, nur der erste Teil ist abgeschlossen -: der war lang genug, fast sechs Jahre lang. Du und ich kennen seine bitteren Kapitel -: eines Tages werden sie der Welt bekannt, vorher muß viel geschehen. Die Geschichte all deiner Irrtümer und ihrer langsamen Überwindung ist stumm und rätselhaft hinein verwoben in den Roman der Heimatlosen. Zwei Linien, zwei mit Energie geladene Kurven liefen parallel: die Kräfte der inneren und der äußeren Emigration wollen sich nun verbinden. Vereinigt sollen sie wirken -: dies ist die Stunde, euer Engel kennt sie, er darf nicht dulden, daß ihr sie versäumt“ (V 541).

132 Michail Bachtin, Die Ästhetik des Wortes, Frankfurt am Main 1979, S. 205. 
sozial nicht festgelegt und kann in seiner Welthaltigkeit jene vergangenen und gegenwärtigen heterogenen Stimmen zusammenführen. Auch die Heteroglossie dieser unhintergehbaren Vielfalt der Rede ist wesentlich für eine adäquate Behandlung des Exils und sein „,internationales Kauderwelsch““ (V 515). ${ }^{133}$ Indem der Roman künstlerische wie außerkünstlerische Gattungen zu integrieren vermag, ist in ihm die präzise soziale Analyse ebenso möglich wie religiös durchwirktes Gedankengut.

Neben diesen Qualitäten ist der Roman die Form, in der der Widerstreit von Ästhetik und Ethik überwunden werden kann. Im Vulkan werden verschiedene Formen des Umgangs mit der ,epochale[n] Denormalisierung durch die Naziherrschaft“"134 im Exil vorgeführt - der apolitische Ästhetizismus Martins, die pazifistische Naivität eines namenlos bleibenden berühmten Schriftstellers, die in abgeschwächter Form auch Benjamin Abel kennzeichnet, die selbstgerechte Frömmigkeit, für die Kikjous Haltung vor Martins Tod steht, oder das parteipolitische Engagement. Erst die Vermittlung der sozialpolitischen mit der ästhetisch-religiösen Sphäre eröffnet einen Weg aus der Isolation, der einen Erfolg versprechenden Kampf gegen Faschismus und nationalistische Ressentiments mit der Beförderung des göttlichen Heilsgeschehens und einem ambitionierten künstlerischen Schaffen verbindet.

Über die Gattungsspezifika des Romans hinaus ist es vor allem die Kunst, die hier in ihrer Qualität als wahrheitsfähiges Medium apostrophiert wird. Während Kikjou als national indeterminierte Figur die Frage, in welcher Sprache der Roman der Heimatlosen verfasst sein soll, als irrelevant abtut (,,Darauf kommt es doch gar nicht an. Ich kann alle Sprachen“" (V 522)), ist es das Wahrheitspostulat, das das Unterfangen so heikel macht (vgl. V 522). Es markiert am schärfsten den Abstand zum Nationalsozialismus und zu Hitler als „Essenz der Lüge“135

133 Dass die Vielsprachigkeit keine babylonische Entzweiung bedeutet, sondern die Gesinnung alle Sprachbarrieren überwindet, wird mehrfach angedeutet, vgl. etwa: „Die deutschen Soldaten [die im Spanischen Bürgerkrieg gegen die Faschisten gekämpft haben, L.Z.], auf ihrem Lastwagen, sangen ein Lied, als sie die zerstörte Stadt Tortosa verließen. Ihre Kameraden, die noch auf dem Posten blieben, sangen mit. Der Text des Liedes ward in spanischer, französischer, deutscher, englischer, holländischer, schwedischer, portugiesischer Sprache vorgetragen. Indessen war die Melodie für alle gleich, und sie sangen im gleichen Rhythmus, kamen nicht aus dem Takt. Das Lied, mit dem die Männer von Tortosa Abschied von den deutschen Brüdern nahmen, war die ,Internationale‘. Kikjou lauschte, schon von der Wolke empor-geschaukelt. Der Engel der Heimatlosen, mit tiefer, melodischer Stimme, summte den Refrain: ,Völker, hört die Signale ....“ (V 538).

134 Lachmann, ,Exil‘ als literarisches Projekt, S. 96.

135 Klaus Mann, Das Wort. In: Mann, Zweimal Deutschland. Aufsätze, Reden, Kritiken 19381942, hg. von Uwe Naumann u. Michael Töteberg, Reinbek 1994, S. 318-327, hier S. 321. 
und verdeutlicht zugleich die große Bedeutung einer wahrhaftigen Kunst: „Die Lüge hat unsere Zivilisation bis an den Rand des Zusammensturzes geführt. Nur das Zurückfinden zur Wahrheit kann uns retten. “136 Das distinkte Merkmal der Dichterinnen und Dichter gegenüber den Vertreterinnen und Vertretern der Politik liegt vor diesem Hintergrund in ihrem Wahr-Sprechen, das auch den Engel kennzeichnet. So bestimmt Klaus Manns in seinem Artikel „Das Wort“ (1941) den Grenzverlauf zwischen Tier, Mensch und Engel entlang der Fähigkeit, zu lügen, die nur dem Menschen zugesprochen wird, da einzig er sich frei zur Wahrheit verhalten könne. Dagegen sei das Lügen den Engeln unmöglich, „weil der eigentliche Kern ihres Wesens Wahrheit ist“"137. Für Kikjous Unterfangen, für dessen Gelingen die dem nationalsozialistischen Zugriff entzogene Wahrheit eine zentrale Rolle spielt, besteht also anders als bei den gescheiterten Projekten seiner Freunde auch deshalb Hoffnung, weil er mit dem Engel Unterstützung von einer Wahrheitsinstanz erhält, die noch dazu epistemischen Anfechtungen gegenüber immun ist. Neben seiner Unfähigkeit zur Lüge entstammt das Wissen, das der Engel über die Menschen und ihre Bedeutsamkeit für den göttlichen Plan vermittelt, einer Sphäre, die menschlicher Überprüf- und damit Falsifizierbarkeit entzogen ist (vgl. V 527).

Der Engel avanciert somit zum Prisma der Vermittlung von Theorie und Praxis, von Wort und Tat, die entscheidend für die gelingende künstlerische Produktion und umgekehrt gerade auch von dieser zu leisten ist. Auf diese Weise wird mit der Verbindung von Schreiben und Handeln ein zentrales Problem des politischen Schreibens überwunden, ${ }^{138}$ an dem Marcel gescheitert war. Die Trennung zwischen drinnen und draußen als Basis der Heimat-Fremde-Dichotomie, die, wie gezeigt, aus ihrer geographischen Verankerung gelöst wurde, wird hier auch in einer anderen Spielart entmachtet: in Bezug auf jenes insbesondere für die Zeit des Nationalsozialismus vieldiskutierte Problem der ,Innerlichkeit‘ des Künstlers und sein Verhältnis zur Außenwelt. ${ }^{139}$ Insofern ist hier Andreas Grünes zu widersprechen, der behauptet, es stünden ,in Der Vulkan nach dem Scheitern der Volksfront antifaschistische Dissidenz, Resignation und Abwendung vom Politischen als Konsequenzen des Exils gleichrangig nebeneinander“140. Deutlich

136 Mann, Das Wort, S. 327.

137 Mann, Das Wort, S. 318.

138 Vgl. Claas Morgenroth, Martin Stingelin u. Matthias Thiele, Politisches Schreiben. Einleitung. In: Die Schreibszene als politische Szene, hg. von Claas Morgenroth, Martin Stingelin u. Matthias Thiele, München 2012, S. 7-33, hier S. 11.

139 Zur Untersuchung dieses Themas in vergleichender Perspektive vgl. Dani Issler, „The World of Yesterday“ versus „The Turning Point“: Art and the Politics of Recollection in the Autobiographical Narratives of Stefan Zweig and Klaus Mann. In: Naharaim, 8/2, 2014, S. 210-226.

140 Grünes, Klaus Mann: Der Vulkan, S. 436. 
werden die Ausweichmanöver gegenüber dem ethischen Imperativ weltpolitischer Verantwortung disqualifiziert und zwar nicht nur hinsichtlich eines gesellschaftlichen Ethos, sondern auch im Hinblick auf die eigene Biographie und das eigene Kunstschaffen.

\subsubsection{Der Vulkan als Offenbarungstext}

Das Prinzip der Überschreitung, das sich in der Transzendierung der Opposition von ästhetizistischer Innenschau und Parteinahme für einen kosmopolitischen Humanismus manifestiert, ist für den gesamten Roman konstitutiv. Dazu heißt es in einem Tagebucheintrag Klaus Manns vom 15. Februar 1939: „Z[auberer (Thomas Mann), L.Z.] sagt etwas Hübsches: die Tendenz zum Auf-Flug im Ganzen. Daher bleibt der Engel ,im Stil‘. Auch der ,ideale Emigrations-Roman“, der geschrieben werden soll (Martin - Kikjou): der Roman will über sich selbst hinaus. Der Mensch will über sich selbst hinaus ..."141 Dieser Gattungsreflexion der Bewegung des Über-sich-Hinaus entspricht auf Romanebene der „AufFlug“ des Engels der Heimatlosen zur „Höchsten Instanz“ (V 545). Es betrifft darüber hinaus aber auch das dem Roman zugrundeliegende Geschichtsbild.

Mochte Klaus Mann das „Verständnis der Mission der Arbeiterklasse“ fehlen, wie Albrecht Friedrich im Zusammenhang mit dem Vulkan aus DDR-Perspektive feststellt, so trifft es für den Roman insgesamt sicher nicht zu, dass „Klaus Mann die Grenzen eines von starken pessimistischen Zügen geprägten spätbürgerlichen Geschichtsdenkens nicht zu durchbrechen "142 vermocht habe. Vielmehr ist gerade das Durchbrechen im Sinne der Überschreitung das tragende Prinzip des Romans, das auch anthropologisch tragend wird, und zwar in Form des Menschen, der sich dem Engelhaften nähern und damit seine nationale Verhaftung überwinden soll. Auch die Architektur des Romans basiert auf diesem Prinzip, wobei die Andeutung einer Überschreitung ins Überirdische nach dem Höhepunkt des göttlichen Appells durch zwei rahmende Briefe geerdet wird. Das Prinzip der Überschreitung manifestiert sich schließlich in der autopoetologischen Dimension des Romans, die sich im Wendepunkt spiegelt. Denn die Fragen, die Klaus Mann bei der Abfassung des Vulkans be-

141 Klaus Mann, Tagebucheintrag, 15. Februar 1939. In: Mann, Tagebücher 1938-1939, hg. von Joachim Heimannsberg, Peter Laemmle u. Wilfried F. Schoeller, Reinbek 1995, S. 86-87, hier S. 87.

142 Friedrich Albrecht, Der Vulkan. Roman unter Emigranten. In: Albrecht, Klaus Mann der Mittler, Bern 2009, S. 37-48, hier S. 44. 
schäftigen, sind dieselben, die seine Romanfigur Martin umtreiben. So heißt es im Wendepunkt:

Ich schrieb mit Eifer, freilich auch mit Zweifeln. „Für wen schreibe ich?“ Die Frage blieb mir immer gegenwärtig. Diese Chronik der vielen Verirrungen und Wanderungen - wer wird sie lesen? Wer wird Anteil nehmen? Wo ist die Gemeinschaft, an die ich mich wenden könnte? ... Unser Ruf geht ins Ungewisse, oder stürzt er gar ins Leere? Bleibt ein Echo aus? Irgend etwas wie ein Echo erwarten wir doch, und sei es auch nur ein undeutliches, weit entferntes. Ganz stumm darf es nicht bleiben, wo so heftig gerufen wurde. ${ }^{143}$

In dem auf der nächsten Seite folgenden Zitat aus dem Vulkan werden die beiden Schreibprojekte explizit überblendet: „,Für wen schreibe ich?‘ Diesmal bin nicht ich es, der seufzt, oder ich seufze doch mit fremdem Atem. Eine meiner Romanfiguren, der junge Emigrant Martin Korella, brütet über dem Emigrantenroman, den ich ihn schreiben lasse und den er übrigens nie vollenden wird." ${ }^{144}$

Auch den Roman der Heimatlosen, den Kikjou weiterschreiben soll, gibt es nicht in abgeschlossener Form, sondern nur als unausgeführten Vorsatz. Nach der Vermittlung der göttlichen Pläne durch den Engel besetzt Kikjou, so wird angedeutet, in der Angelisierung seiner anachoretischen Lebensform die mediale Position des Engels, indem er die ihm zuteil gewordenen Einsichten in die Welt der Menschen trägt. Diese zweite Vermittlungsleistung, die vom Sehen zum Verkünden, wird allerdings nur umrissen und verweist als Leerstelle innerhalb des Romans autopoetologisch auf den Vulkan selbst.

Eine weitere Parallele zwischen Vulkan und Roman der Heimatlosen besteht darin, dass der Vulkan die in ihm für den Roman der Heimatlosen beschriebene montageartig-intertextuelle Narrativierung des Exils selbst umsetzt und das Exil so für zukünftige Generationen bewahrt. Mit den Stimmen von Jesus, Engel und Gott präsentiert auch der Vulkan sich als Medium eines höheren Wissens: Über die göttlich inspirierte Poetologie weist er sich als Offenbarungstext und seinen Autor entsprechend als numinos informierten „revolutionäre[n] Prophet[en]“145 aus. Diesen bestimmt Klaus Mann in dem posthum veröffentlichten Essay „Die Aufgabe des Schriftstellers in der gegenwärtigen Krise“ (1941) als den Künstler, der zukünftige Entwicklungen nicht nur voraussieht, sondern auch durch Agitation der Zeitgenossen zu befördern sucht. In Abkehr von modernetypischen Reduktionstendenzen, nach der im prophetischen Sprechen Gott gestrichen oder substituiert ist, wird im Vulkan die traditionelle Form der Prophetie mit ethischer

143 Mann, Der Wendepunkt, S. 524.

144 Mann, Der Wendepunkt, S. 525.

145 Mann, Die Aufgabe des Schriftstellers in der gegenwärtigen Krise, S. 264. 
Zielsetzung reaktiviert - Gott und die über ihn verbürgte ethische Sendung bilden die tragenden Bezugsgrößen. ${ }^{146}$

Wie in der Etablierung eines exklusiven, die Romanwelt transzendierenden Kommunikationsraums von Gott und Leserinnen und Lesern bereits anklang, beschränkt auch der Wirkungsradius der religiös-ästhetischen Sinnstiftung sich nicht auf die Romanfiguren. Er erstreckt sich, ebenfalls von der konstitutiven Überschreitungsbewegung des Romans erfasst, auf die textexternen Exilanten und Exilantinnen. Folgt man dieser These, dann ist der Vulkan nicht nur aus seinem historisch-politischen Kontext zu verstehen, sondern er strahlt auch wirkungsästhetisch auf ihn zurück. Die Gemeinde, an die sich die Botschaft des Vulkans richtet und der gegenüber sie ihre nobilitierende und normbildende Kraft entfalten soll, ist die der Heimatlosen des Jahres 1939. Sie werden in ihrem Elend und dem asymmetrischen Kampf gegen den Nationalsozialismus durch die Integration in ein Heilsgeschehen mit einem numinos verbürgten Sinn ausgestattet und selbst zu engelhaften Vermittlungsfiguren berufen. ${ }^{147}$

So erhebt Klaus Mann, laut Selbstauskunft ,something like an expert in the science of angels and cherubim“148, das angelische Mittlertum zur vordringlichen Aufgabe der Heimatlosen. Auf die Frage der Welt am Sonntag 1949 nach seiner Situation in den USA antwortet er: „Wir [die europäischen Intellektuellen, L.Z.] müssen versuchen, unserem kulturellen Erbe die Treue zu halten und doch den amerikanischen Einfluß in uns aufzunehmen. Denn es ist die Rolle des Mittlers, zu der wir prädestiniert erscheinen.“149 Für Marlis Thiel trägt der Engel im Vulkan sogar Züge von Klaus Mann selbst: „[E]r [Klaus Mann, L.Z.]

146 Zur ethischen Dimension der Prophetie vgl. Wacker, Poetik des Prophetischen, S. 39. Auch die metaleptische Überschreitungsbewegung ist ein bekanntes Muster der prophetischen Poetik: „Grundlegend für eine Propheten-Autorpoetik ist insbesondere ihre Eigenart, dass sie gemäß dem Postulat des prophetischen ,Gesamtkunstwerks' die Grenzen zwischen empirischem Autor, implizitem Autor und seinen prophetischen Figuren (teilweise) spielerisch verwischt“ (Wacker, Poetik des Prophetischen, S. 77).

147 So sei es „die Rolle des Mittlers, zu der wir [die europäischen Intellektuellen, L.Z.] prädestiniert erscheinen“ (Klaus Mann, An die Redaktion der ,Welt am Sonntag‘. In: Mann, Briefe und Antworten 1922-1949, hg. von Martin Gregor-Dellin, Reinbek 1991, S. 605-607, hier S. 605). Die gleiche Rolle weist er Deutschland als „Mittler-Volk“ zu (Mann, An die Schriftsteller im Dritten Reich, S. 110). Und schließlich wirkt auch Klaus Mann selbst als Mittler mit seinen Bemühungen um Vermittlung unter den Exilantinnen und Exilanten, aber auch in den Gastgeberländern. Zu konkreten Dimensionen und Situationen, in denen sich das Mittlertum Klaus Manns bewährte, vgl. Friedrich Albrecht, Klaus Mann der Mittler. In: Albrecht, Klaus Mann der Mittler, Bern 2009, S. 267-326.

148 Klaus Mann, Brief an Thomas Mann, 13. Oktober 1944. In: K. Mann, Briefe und Antworten 1922-1949, hg. von Martin Gregor-Dellin, Reinbek 1991, S. 527-529, hier S. 527.

149 Mann, An die Redaktion der ,Welt am Sonntag', S. 605. 
stand überall dazwischen, insbesondere für die zerstrittene Emigrationsgemeinschaft eine Integrationsfigur und ein geflügelter Diplomat, bestrebt danach, ein prekäres Gleichgewicht aufrecht zu erhalten." ${ }^{\text {150 }}$ Und während der antifaschistischen Einheitsfront wirkte Klaus Mann als transatlantischer Mittler nicht nur zwischen Kommunisten, Katholiken und Pazifistinnen, zwischen europäischen Exilierten und der US-amerikanischen neuen Heimat; ${ }^{151}$ auch an die Schriftsteller im nationalsozialistischen Deutschland wandte er sich mit dem dringlichen Ruf zur Verständigung, ${ }^{152}$ und in Deutschland selbst erblickte er gar „das Mittler-Volk zwischen Nord und Süd, Ost und West“, das „nicht den Auftrag [hat] zu herrschen, sondern den anderen, schöneren und tieferen: zu versöhnen “"153.

Die Vermittlung des Engels verbindet im Vulkan Politik, Ästhetik und Religion, indem die Priorität des politischen Handelns vor der religiösen Kontemplation vermittels der Kunst zur gottgefälligen Maxime erklärt wird. Darin liegt eine wesentlich Erkenntnis von Kikjou, der feststellt: „Während ich mich am schönen Klang Deines [Gottes, L.Z.] Namens berauschte, habe ich ein dummes, weichliches und verfehltes Leben geführt. [...] Du bist der Herrscher, der gerne auf Bezeugungen der Unterwürfigkeit verzichtet, wenn nur gehandelt wird im Sinn Deines Willens. Wenn nur gehandelt wird ...“ (V 338) Das christliche Register im Vulkan stellt ein Bezugssystem dar, das es erlaubt, den Menschen ins Zentrum zu stellen, dem vor aller juridisch-politischen Formierung Würde zukommt. Der Mensch wirkt politisch gleichermaßen als visionärer Zielpunkt für die Utopie einer Weltdemokratie wie - über eine rhetorische Homogenisierung der antifaschistischen Kräfte - als Kitt in der Gegenwart, indem er weltanschauliche Differenzen transzendiert. Für die Überwindung der gegenwärtigen Misere stellt das Christentum den für Klaus Mann so wichtigen Einheitsgedanken bereit, der die zersplitterten antifaschistischen Gruppierungen zusammenführen und ihre Schlagkraft bündeln und steigern soll.

So überwindet die universalmenschliche Ausrichtung des Christentums diesem Verständnis nach nationalstaatliches Denken und gibt dem erniedrigten Menschen seine Würde zurück. Auf diese Weise stellt es als eine nicht nur der

150 Marlis Thiel, Klaus Mann. Die Sucht, die Kunst und die Politik, Pfaffenweiler 1998, S. 222. 151 Vgl. das Programm seiner Zeitschrift Descision: Es geht unter anderem darum, „eine Solidarität unter fortschrittlichen Geistern zu beweisen und zu stärken, die über alle nationalen Grenzen hinausgeht“ (Mann, Decision, S. 238).

152 Vgl. der eindringliche Appell: ,Jetzt aber und neuerdings hat unser aller Situation sich so verändert und zugespitzt, daß eine Verständigung zwischen Euch und uns zur Notwendigkeit wird. Wir müssen uns einigen, wiederfinden, wieder-verstehen, Kollegen im Dritten Reich! Wir müssen!“ (Mann, An die Schriftsteller im Dritten Reich, S. 102).

153 Mann, An die Schriftsteller im Dritten Reich, S. 110. 
nationalsozialistischen Ideologie widerstreitende, sondern im Kontext moderner Trennungs- und Differenzierungspraktiken grundsätzlich unzeitgemäß erscheinende Lehre das Instrumentarium bereit, um die Fallstricke von Modernisierungsprozessen kritisch $\mathrm{zu}$ hinterfragen, die bei moralischer Indifferenz drohen. ${ }^{154}$ Außerdem werden die entwürdigten Exilantinnen und Exilanten über eine Angelisierung aufgewertet, die die Mangelerscheinungen des Exils in Fülle transformiert. Die Angelisierung lässt sie nicht nur über eine schwerelos-sakrale Ästhetik schön in ihrem Elend werden, sondern auch, im Falle Marions und Kikjous, zu Medien höheren Wissens avancieren. Dieses wird über die Vermittlung im Roman, in dem Angelisches und Ästhetisches jeweils als Medien des Virtuellen, noch Unverwirklichten fungieren, in die Welt getragen.

Der Engel verleiht dem Christentum eine katapulthaften Wirkung, indem im Umschlag von Mangel in Fülle der Sprung über die untragbaren Zeitumstände hinaus imaginiert wird. Einen Vorschein dieser Zukunft gewährt der Engel als ästhetisches Prinzip, der - wie der Roman selbst - als ein „dritter Charakter“ zum „sinnlichen Pfand der unsichtbaren Sittlichkeit““155 wird. Mit dem Umschlag von (exilischem) Mangel in (transhistorische) Fülle und der Vermittlung zwischen Sichtbarem und Unsichtbarem laufen im Engel als einer zwischen Sphären und Zeiten stehenden transnationalen Figur die tragenden, geschichtsphilosophisch temporalisierten Strukturprinzipien des Vulkans zusammen.

Der zentralen Bedeutung dieser beiden Figuren des Dritten entspricht, dass sie sich jeweils selbst thematisieren - in Form des „Exilsroman im Exilsroman“156 (der Roman der Heimatlosen im Vulkan) und des Engels als Figur der Darstellung der Darstellung (des Undarstellbaren). Mit der Figur des Engels wird das Gewicht politischer Handlungen ins Transzendente verlängert und potenziert - die Heimatlosen kämpfen nicht nur gegen den Faschismus, sondern vor allem für eine neue, göttlich verbürgte Ordnung, der sie durch ihr Wirken auf der Erde zuarbeiten können. So ermöglicht es der Engel als heilsgeschichtliche Figur, eine kontrafaktische Zukünftigkeit und damit eine neue Ordnung zu denken, in der der gegenwärtige Zustand der Unmenschlichkeit und eines technokratisch verwalteten Sinn-Vakuums in die utopische Fülle eines neuen Humanismus umschlägt. Auf diese Weise erfolgt über die religiös fundierte transnationale Perspektive nicht nur eine „epische Analyse“, sondern auch eine fundamentale Veränderung in der Bewertung des Exils: Das Exil bezeichnet keinen Zwischen-

154 Vgl. Mann, Das Wort, S. 320. Auch in dieser Hinsicht gibt es Parallelen zu Schiller, der davon ausgeht, dass „alle Aufklärung des Verstandes nur insofern Achtung verdient, als sie auf den Charakter zurückfließt“ (Schiller, Über die ästhetische Erziehung, S. 592).

155 Schiller, Über die ästhetische Erziehung, S. 576.

156 Volz, Sehnsucht nach dem ganz anderen, S. 151. 
beziehungsweise Wartezustand vor der Rückkehr in die alte Heimat, sondern das Vorstadium einer transnationalen Gemeinschaft.

Auch die fragwürdigen Elemente von Religion, insbesondere in ihrer institutionalisierten Form im Kontext des Faschismus, werden im Vulkan reflektiert (vgl. V 152-154) und von Kikjou als Missbrauch der Gotteswahrheit abgelehnt (vgl. V 337/338). Eine strukturell problematische Dimension des Rekurses auf religiöse Strukturen wird offenbar, wenn Klaus Mann in einer Rezension zu Winston Churchills Ansprachen zwischen Januar 1938 und Februar 1941 schreibt, dass die „überholte politische Antithese“ ${ }^{\text {“157 }}$ von Reaktion und Revolution ersetzt sei durch den Gegensatz von gut und böse. In der Konsequenz werden die Nationalsozialisten an anderer Stelle als „,apokalyptische[s] Monster“"158 und „Antichrist“159 selbst tendenziell aus dem Bereich des Menschlichen ausgrenzt. Hier erfolgt eine bei Exilschriftstellern und Exilschriftstellerinnen verbreitete und nicht unbedenkliche Annäherung an die faschistische Freund-Feind-Logik. Thomas Koebner wendet gegen die Ausgrenzung dieser „Wiederentdeckung des Bösen“160 ein, dass „mit dem im Grunde theologisch ausgerichteten Begriff des Bösen die Vorstellung einer Befreiung am Ende verbunden“" 161 ist; in dieser Logik erscheint der Teufel selbst als Teil des religiösen Weltmodells. Dadurch werde der Blick für unliebsame Affinitäten und untergründige Verwandtschaften in diesem scheinbar manichäischen System geschärft. ${ }^{162}$ Klaus Manns Reflexionen bewegen sich in diesem

157 Mann, Blut, Schweiß und Tränen, S. 317.

158 Klaus Mann, Erklärung zum Kriegseintritt der USA. In: Mann, Zweimal Deutschland. Aufsätze, Reden, Kritiken 1938-1942, hg. von Uwe Naumann u. Michael Töteberg, Reinbek 1994, S. 373.

159 Mann, Blut, Schweiß und Tränen, S. 311.

160 Thomas Koebner, Unbehauste. Zur deutschen Literatur in der Weimarer Republik, im Exil und in der Nachkriegszeit, München 1992, S. 213.

161 Koebner, Unbehauste, S. 213.

162 Diese mentalitätsgeschichtlichen Zusammenhänge hat insbesondere Thomas Mann reflektiert; neben dem Doktor Faustus (1947) und seinem Vortrag „Germany and the Germans“ (1945) artikulierte er entsprechende Überlegungen auch im Rahmen der „großen Kontroverse“, die sich an Thomas Manns Weigerung, nach Deutschland zurückzukehren, entzündete. In einer Dialektik, die schon der Argumentation seines Aufsatzes „Die Stellung Freuds in der modernen Geistesgeschichte“ von 1929 zugrunde liegt, geht Thomas Mann davon aus, dass „oft auf Erden von dem Bösen das Gute kommt - und [...] daß oft das Böse kommt aus dem Guten“ (Thomas Mann, Warum ich nicht zurückkehre! In: Die grosse Kontroverse. Ein Briefwechsel um Deutschland, hg. von J.F.G. Grosser, Hamburg 1963, S. 27-36, hier S. 34). In der Konsequenz wird auch die Annahme eines guten und eines bösen Deutschlands abgelehnt und stattdessen von einem Deutschland ausgegangen, das zwar einen „Pakt mit dem Teufel“ eingegangen, deshalb aber nicht verloren zu geben sei, denn: „Die Gnade ist höher als jeder Blutsbrief“ (Mann, Warum ich nicht zurückkehre!, S. 34). 
Fahrwasser, wenn er schreibt, dass die „deutsche Inkarnation des absolut Bösen [...] auf niedrigstem Niveau ein Bruder von Goethes Mephisto“163 sei.

Während die Exilantinnen und Exilanten im Vulkan in ihrem Reden und Handeln teils problematischen Polarisierungen verhaftet bleiben und regressive Sehnsüchte offenbaren, wirkt auch in dieser Hinsicht die angelische Perspektive als Korrektiv. Als der Engel der Heimatlosen mit Kikjou in die Stadt Tortosa fliegt, die in der Schlacht am Ebro zerbombt wurde, bleibt er angesichts der für die Menschen grauenhaften Zerstörung ungerührt: „Der Engel war furchtlos. ,Es wird ein bißchen geknallt.' Er zuckte die Achseln. ,Ich habe anderes mitgemacht.““ (V 534) Von dem übergeordneten Blickpunkt des Engels aus, der gleichwohl nicht immun gegenüber den Gräueln der Zeit ist, ${ }^{164}$ wird das für die menschlich beschränkte Anschauung furchtbare Böse depotenziert, das der Engel der Heimatlosen dann später explizit als Teil eines göttlichen Plans deklariert. Damit spricht er dem Bösen als abhängigem Moment ohne eigene Machtsphäre ontologische Dignität ab. Aus dieser überlegenen Perspektive sind dann die Faschisten auch keine unmenschlichen Bestien, sondern wiederum schlicht Menschen:

„Drüben liegen die Faschisten.“ Der Engel runzelte die Stirn und sah ungnädig aus. Nach einer Pause bemerkte er noch - verächtlich, aber doch schon wieder besänftigt -: „Mein Gott - es sind auch nur Menschen ...“

Durch den überirdischen Filter erscheint die historische Situation zugleich größer und kleiner: Einerseits wird der Kampf gegen den Faschismus über den Rekurs auf das christliche Gedankengebäude apokalyptisch stilisiert und mit jener kulturell verfügbaren Semantik ausgestattet, die größtmögliche Wucht und Dramatik erzeugt. Gleichzeitig erlaubt es das universale religiöse Koordinatensystem, einen unmenschlichen, nicht relativierbaren Blickpunkt $\mathrm{zu}$ installieren, von dem aus die irdische Auseinandersetzung auf Miniaturgröße zusammenschnurrt.

Eine ähnliche Wirkung wird auf Weltebene für den transhistorischen Raum der Kultur reklamiert, in den sich die Exilantinnen und Exilanten aufgehoben wissen dürfen - „Goethe, Lichtenberg, Humboldt stehen brüderlich neben unseren Kameraden, unseren Leidens-Genossen und Mitkämpfern. Das ist eine gute Nachbarschaft und gibt einen schönen Klang“165. In diesem Zusammen-

163 Mann, Blut, Schweiß und Tränen, S. 311.

164 So verwandelt der Engel sich vorübergehend, seine Augen werden zu „leere[n] Höhlen, schwarz und tot“ (V 519), und er erklärt: „,Ich komme zu oft und nah an Widriges heran: es wirkt ansteckend. Manchmal packt es mich, und ich muß selber gräßlich werden [...]““ (V 520). 165 Klaus Mann, Eine schöne Publikation. In: Mann, Zweimal Deutschland. Aufsätze, Reden, Kritiken 1938-1942, hg. von Uwe Naumann u. Michael Töteberg, Reinbek 1994, S. 70-71, hier S. 71. 
hang steht auch die Bewahrung im Medium der Schrift. So wird der Konnex von Leben und Kunst im Vulkan nicht nur über Pathosformeln der bildenden Kunst, sondern auch über die Formgebung der Prosa in Szene gesetzt. Vermittelt über den Engel als numinose Instanz, die dort Bedeutsamkeit zusichern kann, wo das menschliche Auge nur sinnlose Vernichtung sieht, erhält das Leben in der Anarchie Struktur und Sinn in der beziehungsweise durch die Kunst.

Vor diesem Hintergrund ist der Vulkan extratextuell zweifach als strategische Narration lesbar: autobiographisch in dem Bestreben, die eigene, durch das Exil gebrochene Identität durch die Narration jenseits nationalstaatlicher Kategorisierung auf höherer Ebene wieder zu einer Einheit zusammenzufügen, ${ }^{166}$ vor allem aber wirkästhetisch in der bejahenden und agitierenden Botschaft an die Leidensgenossen. Diese werden in ihrem Elend und dem asymmetrischen Kampf gegen den Nationalsozialismus durch die Erhöhung als tragende Exponenten des göttlichen Willens mit einem numinos verbürgten Sinn ausgestattet. Die Botschaft bezieht ihre Autorität nicht nur von der Sphäre des Göttlichen, sondern auch von einer transhistorischen Schicksalsgemeinschaft. $\mathrm{Zu}$ ihr gehören die toten und lebenden Dichter und Mitstreiterinnnen. Sie reicht bis in die Zukunft der Nachgeborenen, für die das Erlebte bewahrt wird. Die Integration in ein höheres, sinnerfülltes Ganzes wird so nicht nur vertikal hinsichtlich des göttlichen Heilsplans erschrieben, sondern erstreckt sich auch horizontal auf die Menschheitsgeschichte, in deren kulturellem Gedächtnis dem Leid der Heimatlosen ein Platz gesichert ist.

Der Preis für diese Bedeutungsumwertung des Exils ist, dass das durch den Nationalsozialismus verursachte Leid geschichtsphilosophisch funktionalisiert wird. Der Sinn, der dem durch Ausbürgerung, Verfolgung und Verlust entstandenen Leid zugesprochen wird, wirft die Frage auf, inwiefern die Taten des nationalsozialistischen Regimes eine Legitimation erfahren - ein Gedanke, der in Anbetracht von Klaus Manns vehementer Verurteilung und Bekämpfung des Faschismus, aber auch angesichts der Thematisierung und Bewahrung dieses Leids im Vulkan eindeutig zu verneinen ist. Auch ist $\mathrm{zu}$ betonen, dass diese Sinnstiftung im Jahr 1939 und damit vor der systematischen Massenvernichtung von Jüdinnen und Juden erfolgt.

166 Vgl. Bronfen, Exil in der Literatur, S. 170. 